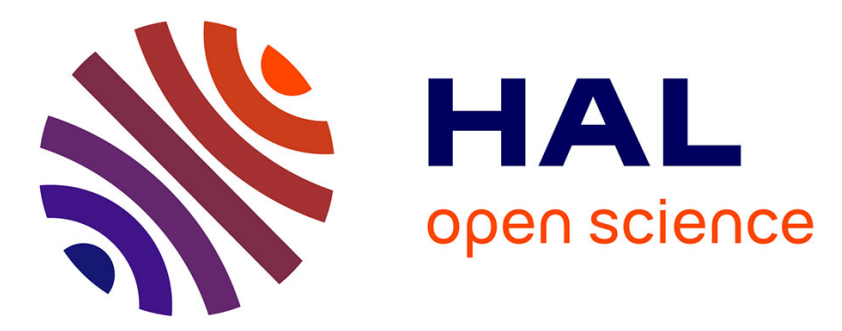

\title{
The influence of environmental conditions on weathering of porous rocks by gypsum: a non-destructive study using acoustic emissions
}

Beatriz Menendez, Christian David

\section{- To cite this version:}

Beatriz Menendez, Christian David. The influence of environmental conditions on weathering of porous rocks by gypsum: a non-destructive study using acoustic emissions. Environmental Earth Sciences, 2013, 68 (6), pp.1691-1706. 10.1007/s12665-012-1861-2 . hal-03266091

\section{HAL Id: hal-03266091 https://hal.science/hal-03266091}

Submitted on 6 Jan 2022

HAL is a multi-disciplinary open access archive for the deposit and dissemination of scientific research documents, whether they are published or not. The documents may come from teaching and research institutions in France or abroad, or from public or private research centers.
L'archive ouverte pluridisciplinaire HAL, est destinée au dépôt et à la diffusion de documents scientifiques de niveau recherche, publiés ou non, émanant des établissements d'enseignement et de recherche français ou étrangers, des laboratoires publics ou privés. 
The influence of environmental conditions on weathering of porous rocks by gypsum: A non-destructive study using acoustic emissions

Beatriz Menéndez and Christian David

Université de Cergy-Pontoise, Laboratoire Geosciences et Environnement Cergy, 5 Mail Gay Lussac, Neuville sur Oise, F-95031 Cergy-Pontoise cedex, France.

beatriz.menendez@u-cergy.fr, tel. 33(0)1 342573 62, fax 33(0)1 34257350

\begin{abstract}
Gypsum is one of the most universally distributed salts in weathered materials but little is known about the influence of environmental conditions on the damage generated by gypsum in stones. To quantify the damage induced by gypsum crystallization acoustic emission techniques are employed to record the elastic energy released during salt crystallization cycles in a limestone. Different environmental conditions have been established during the cooling and drying periods in traditional salt crystallization cycles. During drying two different temperatures $\left(50^{\circ} \mathrm{C}\right.$ and $\left.25^{\circ} \mathrm{C}\right)$ and relative humidity (low, $25 \%$ at $50^{\circ} \mathrm{C}$ and $65 \%$ at $25^{\circ} \mathrm{C}$, and high, 99\%) have been applied. The acoustic emission signals are filtered by a frequency analysis in order to eliminate signals corresponding to external noise or artifacts. Our experimental results show that acoustic emission activity is higher under high relative humidity conditions than under low relative humidity conditions, and also higher when drying at $50^{\circ} \mathrm{C}$ than at room temperature. Microscopic observations on the weathered samples indicated that under high relative humidity conditions and at room temperature gypsum crystallizes not on the sample surface, like in the other samples, but deeper in the inner part of the sample, in good agreement with previously published data. We show that using acoustic emissions as usually done in rock mechanics is also very useful in the study of stone decay and weathering processes in the laboratory.
\end{abstract}

\title{
Keywords
}

Salt weathering, rock damage, stone decay, environmental conditions, acoustic emissions, non destructive technique 


\section{Introduction}

During the next centuries, climat change will have important effects, both direct and indirect, on the environment and the materials of building heritage (Sabbioni, et al. 2004, 2006). Some weathering processes will be accelerated while others will be slowed down. Some parameters to be considered will be the role of raining and calcite solubility on limestone erosion, the answer of clay porous rocks to humidity changes, or rock weathering by freeze-thaw (Grossi et al, 2007) among others.

The XXth century is associated with important changes in the nature of atmospheric pollution. The development of motor vehicles has produced an increasing concentration of volatile organic compounds in the urban air. At the same time substitution of coal by gas and electricity had an inverse effect. Decrease of pollution on cities, even if it has a health policy origin, had also beneficial effect on building stones (Brimblecombe et al, 2006), particularly by the reduction of acid gasses and gypsum (Brimblecombe, 2000). A bibliographic review about the role of atmospheric pollution on monumental stone weathering has been done by Brimblecombe (2003).

The decrease in weathering processes generated by atmospheric pollution and acid rains leads to the conclusion that the effect of climate on the monumental stone weathering, minimum in comparison to the pollution effect until now, will become dominant in the future.

Temperature will probably be the parameter that will most change due to the greenhouse effect. Even if the temperature variation will be of just a few degrees on the average, the way this change will affect building materials should be considered. - Brimblecombe and coworkers (Brimblecombe et al. 2006) estimate the freezethaw risk on stone by the number of days temperature crosses down the $0^{\circ} \mathrm{C}$ threshold, in a day or between two successive days. This effect will be very important in Northern areas where a small increase in temperature can produce a significant increase in the number of negative-positive temperature transitions (Viles, 2005, Grossi et al. 2007).

Salt weathering has been cited by many authors as an universal weathering process affecting different construction materials (Ruiz-Agudo, et al. , 2007) and in natural environments (Turkington and Paradise, 2005). The processes acting during the salt weathering of stone are mainly crystallization pressure, thermal expansion, chemical weathering and "hydratation pressure". The latter consists in dissolution of the anhydrous phase followed by precipitation of the hydrated one (Rodriguez-Navarro et al., 2000; Flatt, 2002, Thaulow and Sahu, 2004). Crystallization pressure has been proved to be the most important mechanism for salt damage, together 
with chemical weathering (Winkler and Singer, 1972; La Iglesia, et al. , 1997; Flatt, 2002; Scherer, 1999, 2004; Steiger, 2005a and 2005b; Coussy, 2006).

Gypsum is one of the most common salts as weathering product in building materials (Hammecker, 1995, Goudi and Viles, 1997, Alves and Sequeira Braga, 2000). It can be found in almost all environments: urban and rural, coastal, etc (Sanjurjo Sanchez et al., 2009). The origin of gypsum present in monuments can be very different: it can be associated with construction materials like plaster or mortar (Silva Hermo et al., 2010), or with $\mathrm{SO}_{2}$ coming from atmospheric pollution reacting with calcium present in the rock forming mineral to form gypsum (Vallet, et al. 2006). Other sources of gypsum may be the bacteria activity (Winkler, 1994) or the reaction of sulfate-bearing solutions percolating through the stone and calcitic stones. Gypsum can be found in most of the crusts, independently of their color or location (Siegesmund et al, 2007). Even considering that the amount of $\mathrm{SO}_{2}$ incorporated into stones will decrease in the future due to lower air pollution, gypsum will stay in the building because of its low solubility. Charola et al. (2007) presented a broad review about phase equilibria of the $\mathrm{CaSO}_{4}-\mathrm{H}_{2} \mathrm{O}$ system and the factors controlling deterioration by gypsum on building materials. As pointed out by these authors, even if its low solubility makes gypsum not so aggressive compared to other salts (Goudie and Viles, 1997), it is not negligible on the long time range. Another factor contributing to the small damaging potential of gypsum is the low speed of the dehydration-hydration reaction between the anhydrous phase (anhydrite) and the dehydrated one (gypsum).

In order to evaluate the future weathering of rocks by gypsum, the environmental conditions controlling damage generation on stones have been investigated, with the idea of obtaining simple "quantitative estimators" of weathering depending on relative humidity and/or temperature. Grossi et al (2008) presented future weathering predictions for $\mathrm{NaCl}$ and $\mathrm{Na}_{2} \mathrm{SO}_{4}$ crystallization, and freeze-thaw. Similar simulations for gypsum were performed using an estimator based on the paper of Lefevre and Ausset (2002). These authors claimed that, when relative humidity is higher than $80 \%$, gypsum will precipitate on the inner part of the rock inducing important damage, whereas it will precipitate on the surface when relative humidity is lower than $80 \%$. Therefore the number of days relative humidity is higher than $80 \%$ has been considered as an estimator of gypsum weathering. The results of this simulation for the XXIst century have been presented in the Ravello workshop in 2009 (Menéndez et al., 2010a). 
Rivas et al (1994) in a granitic monument of NW Spain, found more scales and flakes formed by gypsum in the North façade than in the South façade. The goal of this paper is to provide some clues that gypsum will generate more mechanical damage under high relative humidity than under dry conditions. In order to quantitatively estimate potential damage induced during weathering cycles in laboratory, we used acoustic emissions recording, a non-destructive technique which is well known in rock mechanics (Suarez del Rio, 1982; Zang et al. 1996: Fortin et al, 2009) even if its first application was in the field of rock and soil stability studies (Mc Cabe, et al. 1979; Koerner et al, 1981 and 1982). It is also extensively used in quality control in different areas of industry. The acoustic emission technique was applied to laboratory weathering tests by Grossi et al (1997) for the study of $\mathrm{Na}_{2} \mathrm{SO}_{4}$ crystallization tests, but after that to our knowledge no paper has been published concerning acoustic emission recording during laboratory salt weathering test. It has been applied to the study of the intensity of fracturing in a clay-rich sandstone subjected to cycles of wetting and drying by Bratasz et al. (2008). Cosentino et al. (2009) cited this technique in a review about advances in microgeophysics for in situ engineering and cultural heritage but they did not present any concluding result. Several papers about acoustic emissions in the field of architecture have been presented by a group of the department of structural and geotechnical engineering of the "politecnico" of Turin in Italy (Carpinteri and Lacidogna, 2006) and a group of the department of structural engineering of the "politecnico" of Milan (Anzani et al, 2010). These authors have used acoustic emission to control the evolution of structural damage in historical buildings. Vil'yaminov et al. (2009) recorded acoustic emissions generated during heating experiments in gypsum rock specimens, but in a range of temperatures much higher (up to $1100^{\circ} \mathrm{C}$ ) than the one used in the weathering cycles.

Our goal is to demonstrate that (a) acoustic emission technique is an adequate technique to record damage generated during salt weathering tests in laboratory and (b) gypsum will generate more damage under high relative humidity conditions than under low RH conditions.

\section{Material and methods}

\section{Selected rock}

We chose to work in our experiments on the Paris stone (Pierre de Paris), a limestone of lutetian age which presents several varieties with very different properties. In this study we used the so called "calcaire grossier" variety, the one mostly used in historic buildings of the Paris area (Blanc et al, 2001). The studied sample is a detritic micritic limestone with more than $\sim 90 \%$ calcite, few quartz grains $(\sim 10 \%)$ and small amount of oxides $(<$ 
1\%). No clay minerals have been detected. The porosity is about $36 \%$ and mainly interparticle. The mean pore radius obtained by mercury porosimetry is $12 \mu \mathrm{m}$. Mechanical tests show that the rock has a very low tensile strength, around 1.5 MPa (Angeli et al, 2007). Figure 1 shows some micrographs of the intact rock obtained from (a) magnifying glass, (b) optical microscopy and (c,d) scanning electron microscopy at different magnifications. The quartz and micritic grains can be observed as well as the micritic cement around the grains. On the optical microscopy picture (Fig. 1b) the porosity appears in pink color because it was filled with dyed epoxy.

\section{Experimental setup}

The weathering cycles consisted in conducting $\mathrm{CaSO}_{4}$ crystallization cycles under different environmental conditions, on cubic rock samples with side length $4 \mathrm{~cm}$. In a typical experiment, following a procedure similar to Norm EN 12370, all the limestone samples were immersed in a saturated $\mathrm{CaSO}_{4}$ solution during 2 hours, then dried during a 20 hours period and finally cooled down during 2 hours at ambient temperature. During the imbibition period, as a saturated solution has been used it can be assumed that no dissolution of gypsum crystals take place. During drying more crystals grow up in addition to those previously formed, and we can have both kinds of processes, formation of new crystals and growth of previously formed ones. Six samples were tested simultaneously, each of them with a different combination of drying and/or cooling conditions. For the drying procedure, four samples called hereafter " $\mathrm{H}$ " (for heated) samples were dried in an oven at $50^{\circ} \mathrm{C}$ and two samples called hereafter "A" (for ambient) samples were left drying at room temperature. For the latter the "drying" stage and the "cooling" stage are basically the same thing. In addition three different relative humidity (RH) conditions were applied for drying and cooling periods: 99\%, 25\% and 65\%. Our six samples are named according to the experimental conditions prevailing during the tests: for the heated samples, Hxx-yy where $\mathrm{xx}$ is the relative humidity (in \%) during drying and yy is the relative humidity (in \%) during cooling, and for the samples left at ambient temperature, Azz where zz is the relative humidity (in \%) during drying and cooling. An acoustic emission (AE) channel is assigned to each of the samples, called $\mathrm{CH} 1$ to 6 . Details and correspondence between sample name and AE channel are given in Table 1. As a preliminary step, we have performed two kinds of blank tests, one with a dry sample and another one corresponding to a wetting-drying test with water only. During the "dry" test no AE has been recorded, and during the wet-drying test only few AE have been recorded, much less than during the crystallization tests, so it can be neglected. 
As mentioned before we have used the acoustic emission technique to record continuously the elastic energy released during micro-cracks generation, crack propagation, or crystallization events. This elastic energy propagates in the sample as elastic waves which can be detected and converted into electrical signal by piezoelectric AE transducers. The AE system used to record, process the signals and extract relevant information is an AMSY-5 from the Vallen company which has a maximum capability of recording simultaneously 6 different AE channels. This system has a recording speed of 30000 AE-hits per second and it can store about 2.5 $\mathrm{MB}$ of waveform data per second (40 $\mathrm{MHz}$ sampling rate at 18 bit dynamic range). The AE signals were processed using the Vallen software, in particular Visual TR for the waveform analysis. The threshold for detecting acoustic emissions was fixed at $45 \mathrm{~dB}$ to avoid environmental noise. The AE transducers of type PicoZ (VS550-Z) with size diameter $5 \mathrm{~mm}$ and height $6 \mathrm{~mm}$, also from the Vallen Company, have a bandwidth between 400 to $750 \mathrm{kHz}$. They were pasted directly onto the upper sample surface by a silicon adhesive. A preamplifier AEP4 Hof with a gain of $34 \mathrm{~dB}$ was used to amplify the AE signals. Every time the signal amplitude is higher than the fixed $45 \mathrm{~dB}$ threshold selected by the operator for each $\mathrm{AE}$ channel, the system will record the waveform. On each record several parameters can be measured: rise time, signal duration, maximum amplitude and number of counts. In Figure 2 the meaning of each of these parameters is shown. Other indirect parameters like energy can be calculated from the recorded signals. Each individual hit can be also studied in the frequency domain, and parameters like peak frequency of the spectrum can be obtained for every individual hit. We used one AE channel per sample, each channel is considered to be independent from the other. Therefore in order to eliminate signals associated with electromagnetic noise which is in general recorded by all the channels simultaneously, the whole data set was filtered and such fake "events" were systematically rejected. Indeed in the case where several transducers are placed on a single sample the AE software considers an "event" as the collection of several hits (waves) recorded at times close enough to be considered as being generated by the same physical process (crack, etc).

\section{Experimental results}

Macroscopic properties of weathered samples

Figure 3 shows the samples before and after 20 crystallization cycles. A visual examination of the samples after gypsum crystallization cycles does not reveal any significant change, only little white spots on the surface 
corresponding to location of crystallization (Fig. 3). Cardell et al. (2008) obtained similar macroscopic results for a pure CaSO4 solution in a different crystallization test: they performed crystallization tests for various solution compositions with a permanent solution supply and evaporation at room temperature and $40 \%$ relative humidity. At the optical microscope they observed some scarce subflorescences and some intergranular fissures subparallel to the surface. The evolution of the samples weight with cycles is given in table 1 . It can be observed that the weight does not change very much, just a light increase, mainly on samples dried at high RH which can be explained if samples were not completely dried.

\section{Microstructural study}

At a smaller scale, we investigated under the microscope two kinds of surfaces on the weathered samples after completion of the cycles, the external one and a surface obtained at about $1 \mathrm{~cm}$ in depth cut by a saw without water to avoid salt dissolution. The same kind of inner dry sawed surface has also been prepared in an intact sample for reference. Under magnifying glass (Fig. 4) a striking difference of the external surface of sample A99 compared to all the others can be observed. All samples except sample A99 present a shiny surface and in some case very thin crystals are visible. Sample A65 shows a very uniform shiny surface covering completely the surface. In order to identify the mineralogical phase of calcium sulfate generated during the tests, and because the amount of $\mathrm{CaSO}_{4}$ precipitated in the samples if very low at the end of the cycles, we performed two additional tests of free crystallization from a saturated solution in a crystallizing dish: one under high RH conditions and another one under low RH conditions. The crystallized phases were analyzed by X Ray diffraction and in both cases we found them to be gypsum, whereas anhydrite and hemihydrated phases were not detected.

SEM observations (Fig. 5) of the surfaces show clear differences among the samples. For the "H" samples dried at $50^{\circ} \mathrm{C}$ we can say that under high $\mathrm{RH}$ conditions (H99-65 and H99-99, Fig. 5 b and c) crystals covering completely the sample surface are observed, whereas for samples dried at low RH (H25-65, H25-99, Fig. 5 a and d) the crystals cover the surface but the grain shape can still be recognized. Samples cooled at high RH (Fig. 5 c and d) conditions present more regular crystals and the crystals are quite independent one from the others. In samples cooled at low RH (Fig. 5 a and b), crystals of different size and shape can be observed. In sample H25- 
65 (Fig. 5 a) some quite big $(300 \mu \mathrm{m}$ ) prismatic crystals are observed. In samples H99-65 (Fig. 5 b) and H99-99

(Fig. 5 c) many thin needle-shape crystals are present.

For samples dried at room temperature, few crystals are observed in sample A99 (Fig. 5 f) dried at high RH which explains why the surface does not look shiny under the magnifying glass. Sample A65 (Fig. 5 e) dried at lower RH presents many small crystals on the surface, which seem to have grown following parallel patterns.

Focusing now on inner saw-cut surfaces (Fig. $5 \mathrm{~g}$-l), it can be observed that samples dried at high RH conditions (Fig 5. h-i) present more crystals than samples dried at low RH (Fig. $5 \mathrm{~g}$, j). In the latter crystals cover the grain surfaces but do not fill up the pores. In the sample dried at room temperature and high RH (Fig.5 1), pores are not completely filled up, but gypsum crystals cover the grain surfaces. No crystals are observed in sample A65 (Fig. $5 \mathrm{k}$ ). From our SEM observations of the sample surfaces, we could not identify any feature related to mechanical damage at the grain scale.

\section{Acoustic emission data}

Continuously recording AE during crystallization cycles generates a large amount of data, more than 1800 events, during the 20 cycles. Only the $16^{\text {th }}$ first cycles have been taken into account, and after filtering and removing noisy signals only 750 events were analyzed. Different kinds of waveforms have been obtained during the experiments which can be classified according to 5 main patterns. In Figure 6 we show the different waveforms in the time domain as well as the corresponding frequency spectrum in the Fourier domain. Different parameters have been calculated in order to characterize each pattern like energy (calculated by integrating the squared digitized AE signal for one hit, in energy unit $=10^{-14} \mathrm{~V}^{2} \mathrm{~s}$ ) and peak frequency (in $\mathrm{kHz}$ ). Hits of type A correspond to pulse-like signals with a short duration and a broad frequency spectrum. Hits of type B are characterized by a high frequency and are separated into type B1 and B2, the latter having a duration much larger than the former. Hits of type A and most of the hits of type B2 have been eliminated by the filter based of the arrival time (hits arriving at the same time at different channels): we can consider they are associated with external electromagnetic noise. Hits of types $\mathrm{C}$ and D are low frequency signals which differ by their duration: they do not occur very often, about 20 and 50 hits respectively in total, compared to signals of type B1, B2 and E for which about 400-450 hits have been recorded. Hits of types E are also low frequency signals but with a broader frequency content. In order to simplify the analysis we have decided to consider only two families of 
hits: low frequency hits (peak frequency $<400 \mathrm{kHz}$, types C,D,E) and high frequency hits (peak frequency $>400$ $\mathrm{kHz}$, type B). In Table 2 the characteristics of the hits for the high and low frequency families until cycle 16 are given.

In order to differentiate signals generated by $\mathrm{CaSO}_{4}$ crystallization from signals generated by damaging processes, free $\mathrm{CaSO}_{4}$ crystallization tests at the same RH conditions than in the weathering cycles with $\mathrm{AE}$ signals recording have been conducted. These experiments clearly showed that the signals generated during free crystallization are characterized by a high energy and a low frequency (Fig. 6 F) similar to type C signals but with a much longer duration. Indeed after the maximum recording time (350 $\mu$ s) the free crystallization signals still have an amplitude well above the level of background noise. During cooling no significant AE activity has been recorded. Table 3 shows the characteristics of AE generated during free crystallization cycles. The data presented in this paper have been acquired on one sample for each environmental conditions because of the limited number of $\mathrm{AE}$ channels available and also the long duration of the tests. However we have performed similar tests on different samples of the same limestone and every time the results obtained were in good agreement to those presented here. Therefore we are confident that reproducibility of our experiments is fairly good.

\section{Comparison of acoustic emission activity}

Figure 7 presents the number of acoustic emissions recorded after 16 cycles in total and during the different stages of the experiments; even if 20 cycles have been performed, after the $17^{\text {th }}$ the coupling quality between the samples and the transducers was not good enough to guarantee a correct interpretation of the results. Low frequency events are represented by white bars, high frequency events by black bars. The first striking result is that in all stages there are always more AE recorded for the oven heated samples than for those dried at room temperature, whatever the relative humidity conditions. Secondly, looking at the AE hits distribution per stages in Figure 7, we can see that the number of hits generated during the cooling phase is higher than during the drying stage, although the drying phase has a much longer duration than the cooling one (20h and $2 \mathrm{~h}$ respectively). This observation is in agreement with the results obtained by Grossi et al. (1997). For the sample dried at room temperature and low relative humidity (A65) the number of acoustic emission generated is almost negligible, but for samples dried at high relative humidity, even at room temperature (A99), the AE counts is 
significantly more important. As very few crystals were observed near the surface in sample A99, this tends to show that crystallization occurred preferentially in the sample interior.

Focusing now on the oven dried samples, let us compare the two end members corresponding to both drying and cooling at low (H25-65) and high $\mathrm{RH}(\mathrm{H} 99-99)$ respectively: we can see that H25-65 generates the least of AE of all samples and H99-99 the most. More generally, whatever the drying temperature, samples dried/cooled at high relative humidity conditions generated always more AE than samples dried/cooled at low RH conditions. This is also consistent with the fact that for samples dried at similar RH conditions (H25-65 / H25-99 and H99-65 / H99-99) more AE are recorded in samples cooled at high RH. The distribution between low and high frequency events depends on the experimental conditions. Samples dried and cooled at low RH (H25-65) generate mainly low frequency hits, whereas samples dried and cooled at high RH (H99-99) generate as many high frequency than low frequency hits: at this point we have no clear explanation for that.

Concerning the "mixed" case - samples H99-65 and H25-99 with drying and cooling at opposite RH conditions we can see that during the drying period sample H25-99 generated slightly less AE than sample H99-65, and during the cooling period the sample undergoing more RH changes (H25-99, from $25 \%$ to $99 \%$ ) generated less acoustic emissions than the other one.

\section{Evolution of acoustic emissions with cycles and stages}

To analyze the evolution of acoustic emission activity with the different cycles and stages, we plotted in Figure 8 the evolution of acoustic emission vs. cycle number, in total and for the different stages of the cycles, and in Figure 9 the time evolution of the amplitude for the acoustic emissions recorded during all the cycles.. The most remarkable feature of Figure 8 a is the significantly higher rate of AE generation in sample H99-99. In general, looking at the global AE activity (Fig. 8 a) we observe that samples dried and cooled under high RH conditions generate more AE than samples dried and cooled at low RH at all cycles. We will now discuss the main observations stage by stage.

Saturation stage : during saturation very few AE are recorded and a step by step evolution is observed, except for sample H25-65 which generated the highest number of AE. Special care will be taken to interpret this due to the low number of $\mathrm{AE}$ recorded (sometimes less than one hit per cycle) which cannot be considered as 
representative. Fig. 9 a shows that acoustic emission activity stops after 30 minutes for all the samples except H99-99 and A99 in which AE are generated during the 2 hours but more spread in time after the first 30 minutes. Concerning the AE frequency content during saturation, for samples dried at low RH conditions most of the signals are low frequency signals of type E.

Drying stage: for all the samples the slope of AE activity vs. cycle number is more or less constant except in sample H99-99 where it is higher during the first 6 cycles, then sharply slows down, in contrast with the cooling phase where AE generation increases after cycle 6. On the time distribution of AE during the 20h of the drying stage, we observe two regions where AE activity is concentrated for all the samples, one at the beginning of the cycle between 0 and 7 hours and another one between 15 and 20 hours. To validate this observation and to be sure it does not depend on an external disturbing factor, like for example electronic noise generated every day at the same hour, the amplitude of the AE hit as a function of the clock time has been plotted in Fig. 9 d, because the cycles did not always begin at the same time. In this plot the distribution is more uniform which validates the fact that our observation on data clustering in Fig. $9 \mathrm{~b}$ is not an artifact. Concerning the AE frequency content during drying, for samples dried at low RH conditions (H25-65, H25-99 and A65) mainly type E signals have been recorded. The same is true for samples dried at high RH conditions (H99-65, H99-99 and A99) but for sample H99-65 a significant amount of type D signals have been found. For sample dried at high RH conditions, mainly all the signals are of type B

Cooling stage: during the cooling stage, a constant rate of AE generation with cycles is observed, except for sample H99-99. During each cooling period most of the AE is emitted during the first 30 to 45 min with a rather high amplitude, but samples H99-65 and H99-99 generated AE all over the cooling phase. On the average these two samples generate AE with higher amplitude than the samples dried at low RH conditions. As we already mentioned during the cooling period the number of $\mathrm{AE}$ hits is higher than during the drying period even though the drying period is much longer than the cooling one. In addition for the samples dried at high RH those cooled at high RH emitted twice as much AE than those cooled at low RH. Concerning the AE frequency content during cooling, all samples show mainly type E signals. Samples H99-65 and H25-99, dried and cooled at different RH conditions show also few type C-D signals and also type E.

\section{Discussion}


We have presented a set of experimental data that confirm that weathering produced by gypsum crystallization in rocks is more intense at higher relative humidity. We also provided some microscopy observations that show a variety of different microstructures depending on the thermodynamic conditions each sample had experienced during the tests. Can we come up with a general interpretation of this data set?

\section{Interpretation using phase diagrams}

Figure 10 represents the CaSO4 phase diagram proposed by Charola et al. (2007) on which we added the relative humidity - temperature $(\mathrm{RH}-\mathrm{T})$ paths followed by our different samples, in order to interpret AE activity in relation to the phase transitions supposed to happen during cycles.

Drying stage: during drying $\mathrm{H} 25-65$ and $\mathrm{H} 25-99$ follow similar changes, from solution to oven heated at $50^{\circ} \mathrm{C}$ and $25 \%$ RH. Looking at Figure 10, in the case of drying at low RH, if we consider that during the imbibition period existing crystals were not dissolved, these crystals in sample H25-99 cross both limits, gypsum-anhydrite and gypsum-hemihydrate, but crystals in sample H25-65 only cross one limit, the gypsum-hemihydrate limit. This can explain why H25-99 cooled at high RH generates more AE than H25-65. For samples dried at high RH, H99-65 and H99-99 also follow the same RH - T path, but in this case the preexisting crystals of sample H99-99 cross the gypsum-anhydrite limit and those of sample H99-65 remain in the anhydrite equilibrium zone. This can explain why H99-99 generates more AE than sample H99-65 cooled at low RH. For the drying stage, we can conclude that the more the boundaries crossed on the phase diagram, the most AE generated.

$\underline{\text { Cooling stage: }}$ there are no similar RH - T paths for the cooling stage, either samples start from a common point (H25-65 - H25-99 and H99-65 - H99-99), or samples arrive to a common point (H25-65 - H99-65 and H99-99 H25-99). In such a situation a simple rule cannot be found. The number of AE generated does not depend directly of the number of bounds crossed in the phase diagrams. For example sample H99-99 crosses just one limit (gypsum-anhydrite) and sample H25-99 crosses the two limits but the former generated much more AE that the latter. Sample H99-65 is not crossing any limit but generates more AE than sample H25-99 crossing all the limits.

Saturation stage: the results obtained during the saturation stage cannot be easily interpreted, too few signals have been generated to be representative. 
Although promising for the behavior observed during the drying stage, it is difficult to explain the differences in AE activity on the basis of the phase diagram only. The kinetics of the gypsum-anhydrite reaction is too low to produce anhydrite in this kind of experiments, anhydrite does not crystallize in water with measurable rate at temperatures below $70^{\circ} \mathrm{C}$ (Freyer and Voigt, 2003). This is consistent with the fact that that only gypsum has been generated in our free crystallization tests at the same environmental conditions. Concerning the gypsumhemihydrate reaction Freyer and Voigt (2003) locate the metastable transition temperature of gypsumhemihydrate between 80 and $110{ }^{\circ} \mathrm{C}$ on the solubility diagram. These two reasons explain the fact that only gypsum crystallize at the selected environmental conditions (T, RH and time).

Looking at more complicated environmental paths during experiments will help us in our interpretation. Samples H99-99, dried and cooled at high RH, and H25-99, dried at low RH and cooled at high RH show different acoustic emission generation during the cooling period. Similar observation can be done on sample H25-65 and H99-65, dried at different RH conditions but cooled at the same RH conditions show a different behavior during the cooling period. On the other hand, samples H99-65 and H99-99 dried at the same RH conditions show a quite different behavior during the drying period. The same difference is observed between sample $\mathrm{H} 25-65$ and H25-99 but with less importance. In both cases samples cooled at high RH show more AE during the drying period that samples dried at the same RH but cooled at low RH. It can be concluded that RH conditions during the cooling period will control the damage generated during drying in the next cycle. One possible explanation is that during the saturation phase the $\mathrm{CaSO}_{4}$ is not dissolved, for H99-99 and H25-99 gypsum remains in the sample but for H25-65 and H99-65 it is some hemihydrated (or anhydrite) crystals that could remain. The phase of crystals present at the beginning of drying will then control the generated damage.

Another explanation to the observation that samples cooled at high $\mathrm{RH}$ generate more AE during the drying period than samples cooled at low RH can be given by the growing pattern of crystals: in samples cooled at low RH crystals are more intricate among them and present a more planar shape (Fig. 5) but in samples cooled at high RH crystals are more "independent", with crystallographic faces better defined. In the last case crystal growth during drying period could generate a pressure against pore walls higher than in the case of more tabular crystals.

During cooling period a similar trend is observed: samples H25-65 and H25-99, dried at low RH conditions but cooled at different RH do not show similar number of acoustic emissions, it is higher in samples cooled at high 
RH. The same behavior, but with much more difference, is observed in samples H99-65 and H99-99, dried at high RH. In this case the drying conditions are the ones that control the acoustic emission activity during the cooling stage. During cooling samples dried at lower RH show less AE activity that samples dried at high RH conditions. Both samples H25-65 and H25-99 cross the (b) line on Figure 10. It can be supposed that the cooling time was not long enough to permit hemihydrate to hydrate into gypsum in sample H25-65. For sample H99-99 and H25-99 it can be considered that due to the high RH during drying (99\%) gypsum was formed that controls the AE activity during cooling.

Comparing environmental conditions paths on Figure 10 for samples H25-65 (dry condition in oven) and A65 (dry condition in laboratory environment) it can be observed that $\mathrm{H} 25-65$ crosses over the phase equilibrium line between gypsum and hemihydrate but not A65 that crosses just the gypsum-anhydrite limit. It can be expected that due to the low kinetics of the gypsum-anhydrite dehydration/hydration reaction less damage will be caused at room temperature.

At room temperature the sample tested at high RH conditions (A99) shows more AE than the sample tested at laboratory $\mathrm{RH}$ conditions (A65). For samples dried at $50^{\circ} \mathrm{C}$ the same difference is observed; sample tested at high RH conditions (H99-99) shows more AE than sample tested at low RH conditions (H25-65). These observations confirm also our initial assumption.

\section{Interpretation using microstructural information}

Our microstructural study allowed us to get a better view into crystallization patterns in the different samples. We found in particular that in the samples dried at high $\mathrm{RH}$ crystals get into the pores deeper than in samples dried at low RH as can be observed in Figure 5. During drying at low RH crystals cover the grains but pores are not completely filled up, generating lower crystallization pressures than at high RH conditions. Only gypsum was detected, probably because gypsum hydration/dehydration/solution reactions are very slow, so that equilibrium has not been reached at the end of each stage of the cycles, mainly during the solution and cooling stages. Even if the AE has slowed down at the end of these periods we cannot be sure that the time was enough to allow finishing the processes. For example during drying a "reactivation" of the AE activity after 15 hours is observed that could be linked to some water leaving the crystals. 
Another explanation can be found in Vil'yaminov et al (2009): these authors distinguish two types of water in gypsum: (a) chemically bound water i.e. the water content in the crystalline mineral lattice, with bond energy of $800 \mathrm{~kJ} / \mathrm{mol}$, and (b) physically bound water due to adsorption processes, with bond energy of $120 \mathrm{~kJ} / \mathrm{mol}$. They claim that to allow gypsum to loose the chemical bound water it is necessary to heat up to $140-150^{\circ} \mathrm{C}$, to form the hemihydrate. The physically bound water will turn into free water at $60-70^{\circ} \mathrm{C}$. They did not take in account the relative humidity conditions. Considering the temperatures proposed by these authors in the experiments presented here just a loss of adsorbed water without any dehydration process can take place. Vil'yamov et al. (2009) results explain better our results than the Charola et al. (2007) phase diagram, may be due to the kinetics of the reactions. In this case during the drying stage samples H25-65 and H25-99 would lose physical water but not H99-65 and H99-99. The recorded AE show that samples H99-99 and H99-65 generate more AE than samples H25-65 and H25-99. We can conclude that when adsorbed water remains on the gypsum more damage is generated on the samples.

Although many acoustic emissions have been recorded in our experiments, some of them with a high frequency content which probably are not associated with crystallisation events, surprisingly no cracks indicating mechanical damage could be observed under the SEM. However, we were looking primarily to the sample surface, and the lack of damage at the surface does not rule out the existence of pervasive damage deeper below the surface, where crystal growth inside a pore with limited size can generate important stress concentration on the surrounding grains. Such stress concentrations probably do not occur at the free boundary of our samples which have been investigating under the SEM.

\section{Conclusions}

Two main conclusions can be drawn, the first one concerns the environmental conditions controlling weathering generated by gypsum and the second one, the fact that acoustic emissions techniques are appropriate for investigating and monitoring salt crystallization and associated damage in porous media.

Our experimental results confirm the initial assumption that weathering produced by gypsum crystallization in rocks is more intense when the relative humidity is high than when the relative humidity is low. In addition the temperature effect cannot be neglected: in samples dried at room temperature the number of acoustic emission is much smaller than in samples dried in an oven at $50^{\circ} \mathrm{C}$. One explication could be found in Hammecker (1995): 
during the evaporation tests two stages are observed, a first one with fast evaporation rate conducting to salt precipitation on the sample surface and a second one, slower, producing salt precipitation on the inner part of the sample. Low RH drying conditions will improve "stage 1" evaporation with surface precipitation, whereas drying at high RH will favor longer "stage 2" associated with precipitation in the inner part of the sample.

The second general conclusion is that we showed that using the acoustic emission technique is very appropriate for monitoring salt crystallization processes during laboratory weathering tests, in agreement with the results of Grossi et al. (1997). By extension it is also very helpful to record the damage induced in the rock by salt crystallization. This technique can also be used to determine the environmental conditions controlling such damage in stones. In more detailed studies the analysis of AE permits to localize where damage is produced within the sample if a set of several AE transducers is distributed at the sample surface in order to apply localization methods similar to those used for earthquake localization. The waveform analysis can allow us to differentiate waves generated by different physical processes: hydration/deshydration, crystallization and microcracking.

The study presented here is just the beginning of a more ambitious project concerning the fine determination of the environmental conditions controlling salt weathering in rock samples, focusing more precisely on relative humidity, temperature but also on the nature of the salts. Indeed in the tests presented here gypsum has been used as the weathering salt, but other salts of mixtures of salt are also present in buildings. We have already done some tests with different salts (sodium sulfate, sodium chloride and magnesium sulfate) and some of these results have been presented at the CRYSPOM II workshop (Menéndez et al, 2010b). These results confirm that AE activity during the cooling stage is higher than during the drying one for these salts too. However in these tests the relative humidity was not controlled but it can be assumed that it remained constant during the tests. More experiments will be done at RH conditions varying by steps of $10 \%$, and with longer tests to allow equilibrium to be reached at each stage. We plan also to study the weathered samples under environmental scanning microscopy which will permit to observe the crystals formed in the samples at the same environmental condition they crystallized.

\section{Acknowledgements}


We want to thank Y. Candelier, V. Brouzet and E. Zeitoun, undergraduated and graduated students in our laboratory for their work during their projects that allowed us to define the protocol for the recording of acoustic emissions during the salt crystallization cycles. We would like to thank also the "Conseil Général duVal d'Oise" for their financial support. Finally we thank J-C Colombier (UCP) and Dr. Herbert Karzel (Vallen Systeme $\mathrm{GmbH}$ ) for technical support. Finally we thank the reviewers for their constructive comments and suggestions and especially reviewer 1 for his ideas that contributed to improve our paper

\section{Bibliography}

Alves, CAS. and Sequeira Braga, MA (2000) Decay effects associated with soluble salts on granite buildings of Braga (NW Portugal). Environmental Mineralogy: Microbial Interactions, Anthropogenic Influences, Contaminated Land and Waste management. Book Series, 9, Mineralogical Society of Great Britain \& Ireland: London, UK, 2000; cap. 10, pp 181-199

Angeli M, Bigas J.P, Benavente D, Menéndez B, Hébert R and David D (2007) Salt crystallization in pores : quantification and estimation of damage. Environmental Geology 52:187-195

Anzani A, Binda L, Carpinteri A, Invernizzi S and Lacidogna G. (2010) A multilevel approach for the damage assessment of historical masonry towers. J. Cultural Heritage, doi : 10.1016/j.culher.2009.11.008

Blanc A, Gély J-P and Viré M (2001) Le calcaire lutetien, ses carrières, son utilisation dans les monuments. In «Le lutetien la pierre de Paris » 38-46. Muséum d'histoire naturelle Ed.

Bratasz L, Jakiela S, Lasyk L and Kozlowski R (2008) Direct monitoring of damage in clay-containing sandstone by acoustic emission. Proc. 11th International conference on deterioration and conservation of stone. Torun, Pologne, 2008

Brimblecombe P (2000) Air pollution and architecture, past, present and future. Journal of Architectural Conservation 6-2:30-46 
Brimblecombe P (2003) The Effects of Air Pollution on the Built Environment. World Scientific Publishing Company 448 p.

Brimblecombe P, Grossi CM and Harris I (2006) Climate change critical to cultural heritage. Heritage, Weathering and Conservation. Fort, Alvarez de Buergo, Gimenez-Heras \& vazques-Calvo eds. Taylor \& Francis Group, London. 387-393

Cardell C, Benavente D and Rodriguez-Gordillo J (2008) Weathering of limestone building material by mixed sulfate solutions. Characterization of stone microstructure, reaction products and decay forms. Material Characterization 59:1371-1385

Carpinteri A and Lacidogna G (2006) Damage monitoring of an historical mansory building by the acoustic emission technique. Materials and Structures 39: 161-167

Charola AE, Pühringer J and Steiger M (2007) Gypsum: a review of its role in the deterioration of building materials. Environmental Geology 52:339-352

Cosentino PL, Capizzi P, Fiandaca G, Martorana R and Messina P (2009) Advances in microgeophysics for engineering and cultural heritage. Journal of Earth Science 20(3):626-639

Coussy O (2006) Deformation and stress from in-pore drying-induced crystallization of salt. J the Mechanics and Physics of Solids 54:1517-1547

FlattR.J (2002) Salt damage in porous materials: how high supersaturations are generated. J Crystal Growth 242 : $435-454$

Fortin J, Stanchits S, Dresen G and Gueguen Y (2009) Acoustic Emissions Monitoring during Inelastic Deformation of Porous Sandstone: Comparison of Three Modes of Deformation. Pure and Applied Geophysics 166 (5-7):823-841

Freyer D and Voigt W (2003) Crystallization and phase stability of CaSO4 and CaSO4-based salts. Monatshefte für Chimie 134:693-719

Goudie A and Viles, H (1997) Salt Weathering Hazards; John Wiley \& Sons: London, 1997; 241 p. 
Grossi CM, Esbert RM, Suarez del Rio LM; Montoto M and Laurenzi-Tabasso M (1997). Acoustic emission monitoring to study sodium sulphate crystallization in monumental porous carbonate stones. Studies in Conservation 42(1997):115-125

Grossi CM, Brimblecombe P and Harris I (2007) Predicting long term freeze-thaw risk on Europe built heritage and archaeological sites in a changing climate. Science of the total Environment 377:273-281

Grossi CM, Brimblecombe P, Menéndez B, Benavente D and Harris I (2008) Long term change in salt weathering of stone monuments in North-West France, Proc. 11th International conference on deterioration and conservation of stone. Torun, Pologne, 2008

Hammecker C (1995) The importance of the petrophysical properties and external factors in the stone decay on monuments. PAGEOPH 145:338-361

Koener RM, McCabeWM. and Lord AE (1981) Overview of acoustic emission monitoring of rock structures, Rock Mechanics 14:27-35

Koerner R and Lord AE (1982) Use of acoustic emissions to predict ground stability. Report No. FHWA/RD82/085, Federal Highway Administration, U.S. Department of Transportation, Wash. DC

La Iglesia A, Gonzalez V, Lopez-Acevedo V and Viedma V (1997) Salt crystallization in porous construction materials. I Estimation of crystallization pressure. J. Crystal Growth 177:111-118

Lefèvre RA and Ausset P (2002) Atmospheric pollution and building materials : stone and glass. In Natural Stone, Weathering Phenomena, Conservation Strategies and Case Studies. Siegesmund, S. Weiss, T \& Vollbrecht, A. Eds. Geological Society, London, Special Publications, 205:329-345.

McCabe WM, Koener RM and Lord AE (1979) Acoustic emission (microseismic) monitoring for ground control. Proc. Rapid Excavation and Tunneling Conference, A.C. Maevis and W.A. Hustrulid Eds, Atlanta, GA.

Menendez B, Grossi CM, Brimblecombe P, Benavente D, Déqué M and Harris I (2010a) Stone weathering predictions based on climate change models in North-West France, (Abstract) Cultural Heritage and Climate Change, Proceedings of the Workshop "Climate Change and Cultural Heritage", Ravello, 14-16 Mai 2009, and European Master-Doctorate Course on Vulnerability of Cultural Heritage to Climate 
Change, Council of Europe, Strasbourg, 7-11 September 2009, R.-A. Lefèvre \& C. Sabbioni Eds, Edipuglia Publ., Bari., 2010

Menéndez B, David C, Zeitoun E, Candelier Y and Brouzet V (2010b) Using acoustic emission techniques to determine new estimators for salt damage in rocks. CRYSTOM II, Brienz (Switzerland) June 2010.

Rivas T, Lamas, BP and Silva, B (1994) Plaque-shedding by granite in the Monastery of San Martìn Pinario (Santiago de Compostela, NW Spain). 3rd. Int. Symp.: The Conservation of Monuments in the Mediterranean Basin, Venice, 737-741.

Rodriguez-Navarro C, Doehne E and Sebastian E (2000) How does sodium sulfate crystallize? Implications for the decay and testing of building material. Cem Concr Res 30: 1527-1534

Ruiz-Agudo E, Mees F, Jacobs P and Rodriguez-Navarro C (2007) The role of saline solution properties on porous limestone salt weathering by magnesium and sodium sulfates. Environmental Geology 52: 269-281

Sabbioni C, Cassar M, Brimblecombe P, Tidblaud J, Kozlowski R, Drdacky M, Saiz-Jumenez C, Grontoft T, Wainwright I and Arino X (2004) Global climate change impact on built heritage and cultural landscapes. in 6th European Commission Conference on Sustaining Europe's Cultural Heritage. Research to Policy, London September 2004

Sabbioni C, Cassar M, Brimblecombe P, Tidblaud J, Kozlowski R, Drdacky M, Saiz-Jumenez C, Grontoft T, Wainwright I and Arino X (2006) Global climate change impact on built heritage and cultural landscapes. in Heritage, Weathering and Conservation. Fort, Anvarez de Buergo, Gimez-Heras \& Vazques-Calvo eds. Taylor \& Francis Group, London. 395-401

Sanjurjo Sanchez J, Alves CAS, Vidal Romani JR and Fernandez Mosquera D (2009) Origin of gypsum-rich coatingson historic buildings. Water Air Soil \& Pollution 204:53-68

Siegesmung S, Török A, Hüpers A, Müller C and Klemm W (2007). Mineralogical, geochemical and microfabric evidences of gypsum crust : a case study from Budapest. Environmental Geology 52:385-397

Silva Hermp B, Prieto Lamas B, Rivas Brea T, Pereira Pardo L (2010) Gypsum-induced decay in granite monuments in Northwestern. Materiales de Construcción 60:97-110 
Scherer GW (1999) Crystallization in pores. Cem Concr Res 29:1347-1358

Scherer GW (2004) Stress from crystallization of salt. Cem Concr Res 34:1613-1624

Steiger M (2005a) Crystal growth in porous materials. I The crystallization pressure of large crystal. J Crystal Growth 282:455-469

Steiger M (2005b) Crystal growth in porous materials. II Influence of crystal size on the crystallization pressure. J Crystal Growth 282: 470-481

Suarez del Río L.M (1982).- Estudio petrofísico de materiales graníticos geomecánicamente diferentes. Tesis Doctoral. Facultad de Geología, Universidad de Oviedo (España).

Thaulow N and Sahu S (2004) Mechanism of concrete deterioration due to salt crystallization. Mater Charact 53: $123-127$

Turkington AV and Paradise TR (2005) Sandstone weathering: a century of research and innovation, Geomorphology 67: 229-253

Vallet JM, Gosselin C, Bromblet P, Rolland O, Vergès-Belmin V and Kloppmann W (2006) Origin of salt in monuments degradation using sulphur and oxygen isotopes: First results of the Bourges cathedral (France). J. Geochemical Exploration 88:58-362

Viles HA (2005) Implications of future climate change for stone deterioration. In Natural Stone, Weathering Phenomena, Conservation Strategies and Case Studies. Weiss and Volbrecht Ed. Geological Society, London, Special Publication, 407-418

Vil'yaminov SV, Voznesensky AS, Nabatov VV and Shkuratnik VL (2009). Regularities and mechanisms of thermal acoustic emission in gypseous rocks. Journal of Mining Science 45 (6):533-540.

Winkler EM (1994) Stone in Architecture, Properties and Durability, $3^{\text {rd }}$ rev. and extended edition. SpingerVerlag, New York, $313 \mathrm{p}$

Winkler EM and Singer PC (1972) Crystallization pressure of salts in satone and concrete. Geological Society of America Bull 83 (11):3509-35013 
Zang A, Wagner CF and Dresen G (1996) Acoustic emission, microstructure, and damage model of dry and wet sandstone stressed to failure. Journal of Geophysical Research-Solid Earth 101 (B8):17507-17521 

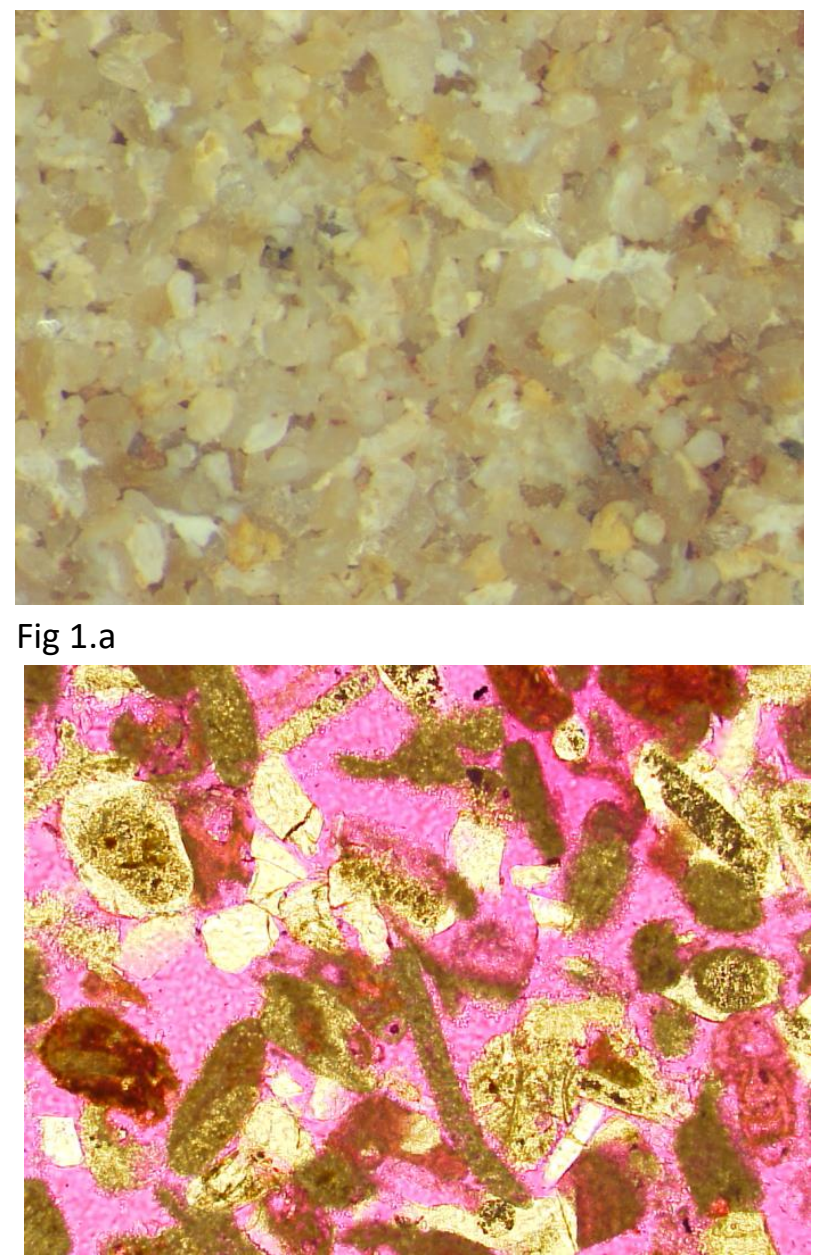

\section{Fig 1.b}

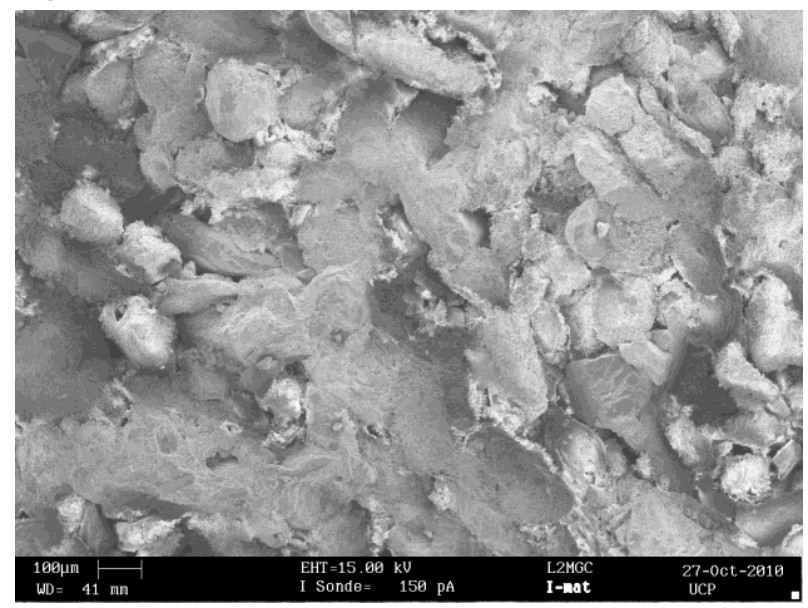

Fig 1.c

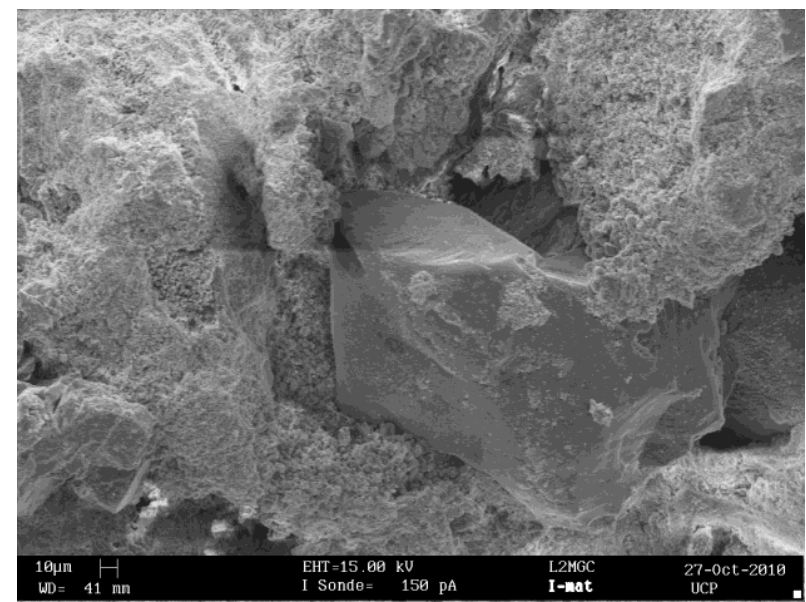

Fig 1.d

Fig. 1 a) Magnifying glass, width of the picture about $3 \mathrm{~mm}$, b) Optical microscopy photograph of a slice impregnated with a rhodamine dyed epoxy, width of the picture about $1 \mathrm{~mm}$. c) general view of a saw cut surface under SEM, mineral grains and micrite matrix covering them can be observed. d) Detail of a grain surrounded by micritic matrix. 


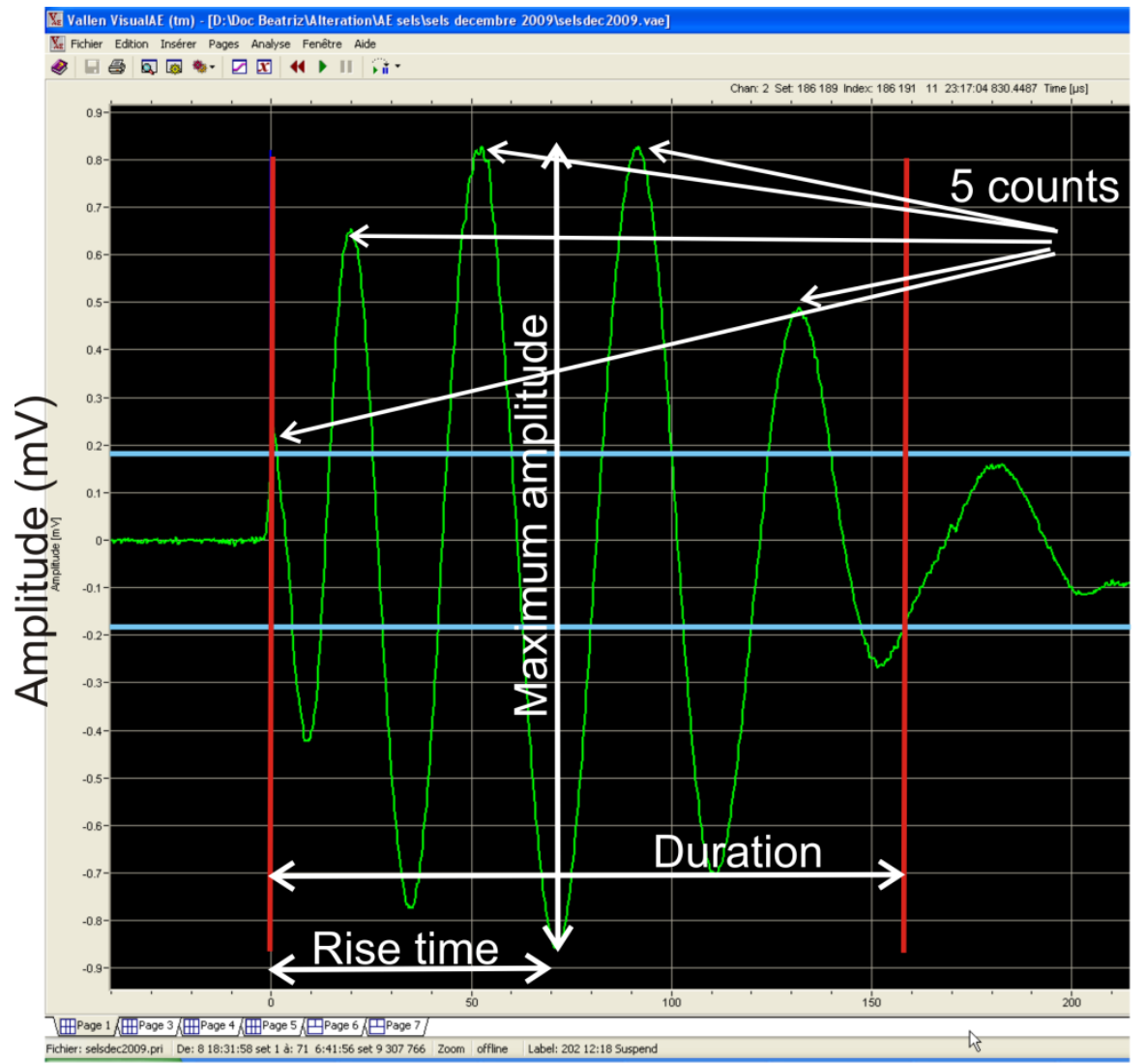

Time $(\mu \mathrm{s})$

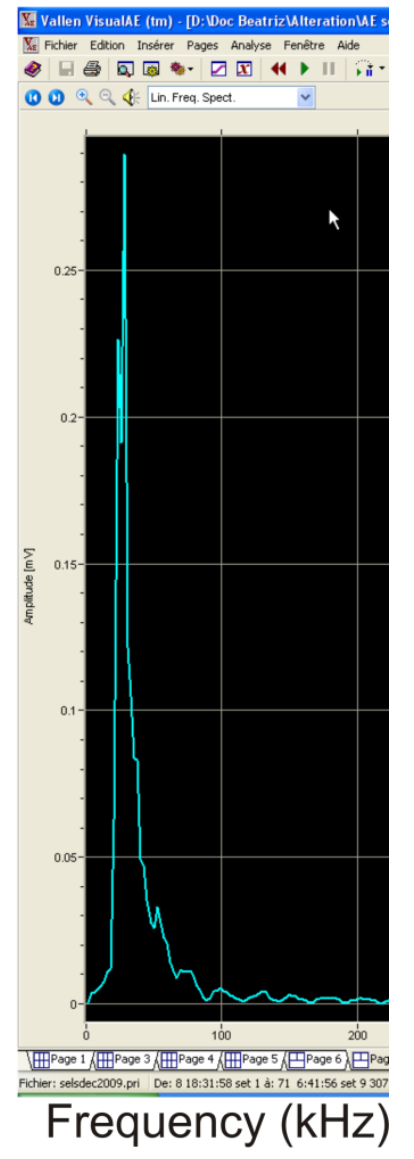

Fig. 2 On the left, signal in the time domain. Typical AE parameters are pointed out. On the right we can see the same signal in the frequency domain. 

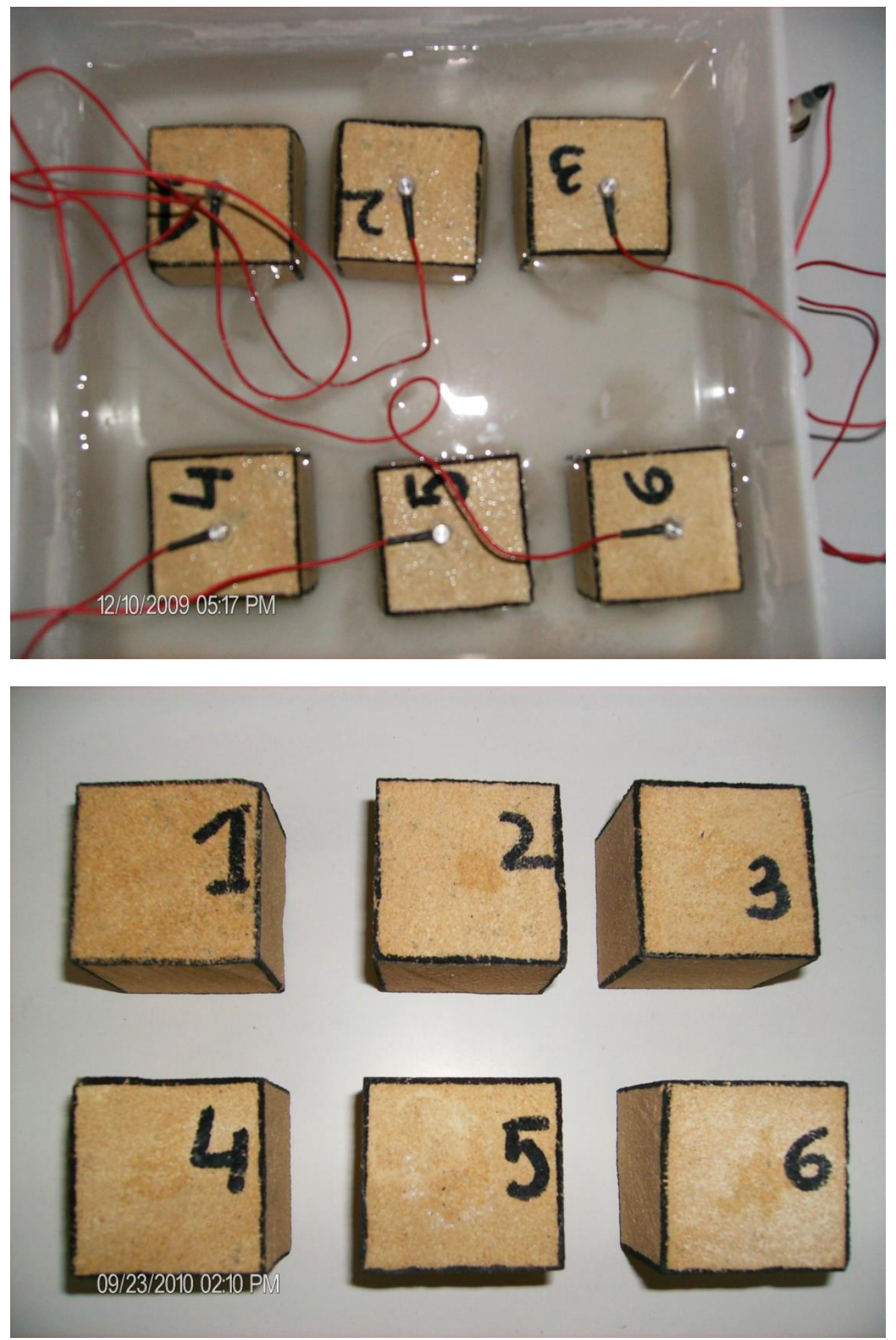

Fig. 3 The rock samples before and after the cycles. Top picture: immersed samples with the acoustic emission transducers pasted onto the samples by a silicon adhesive. Bottom picture: samples some months after the weathering cycles, with light gypsum efflorescences on the surface. 

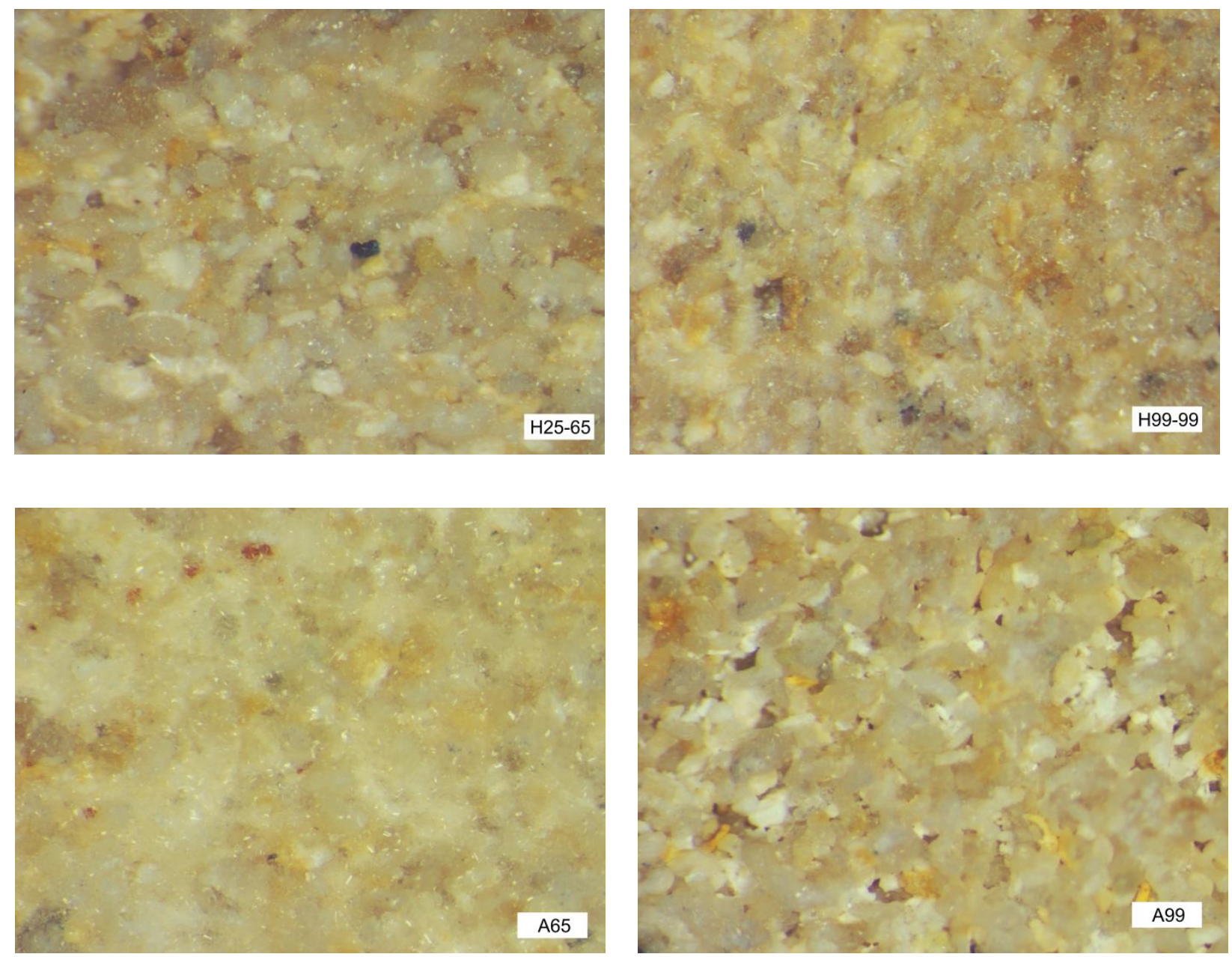

Fig. 4 Magnifying glass pictures for samples H25-65, H99-99, A65 and A99. Width of the picture about 3 mm 


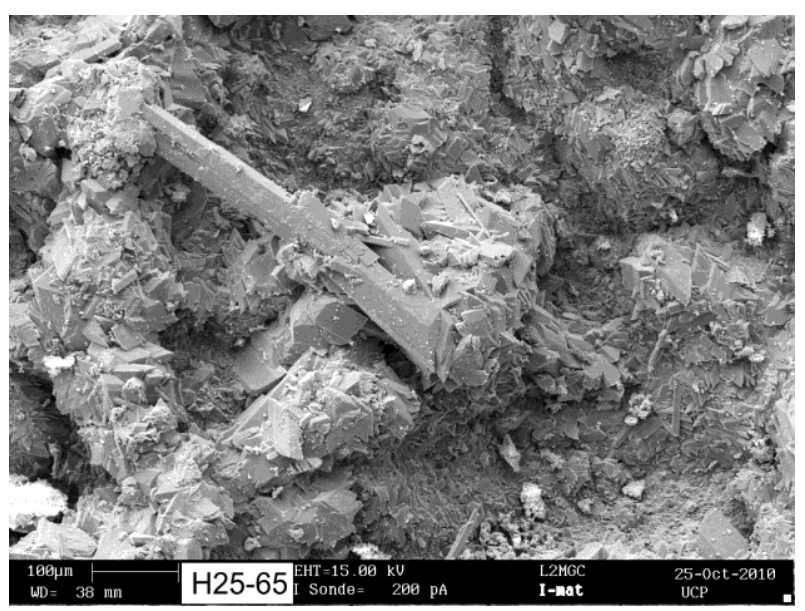

a

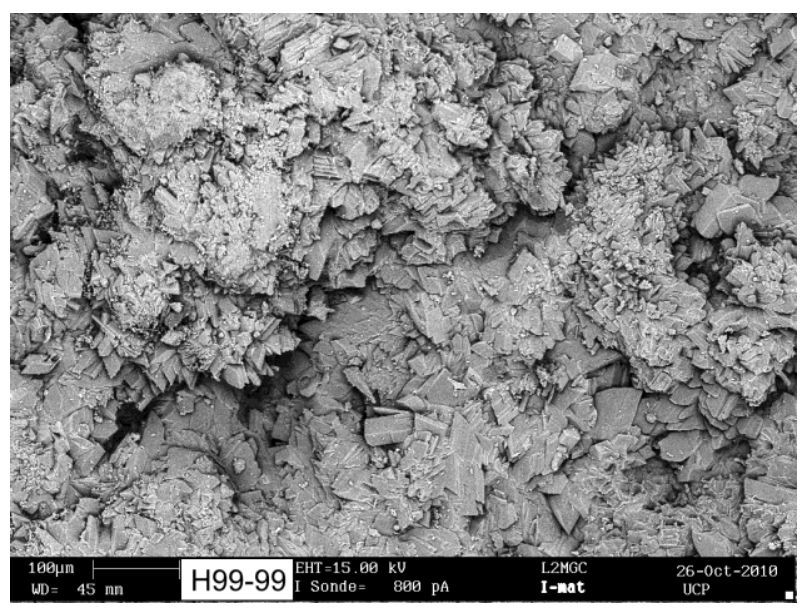

c

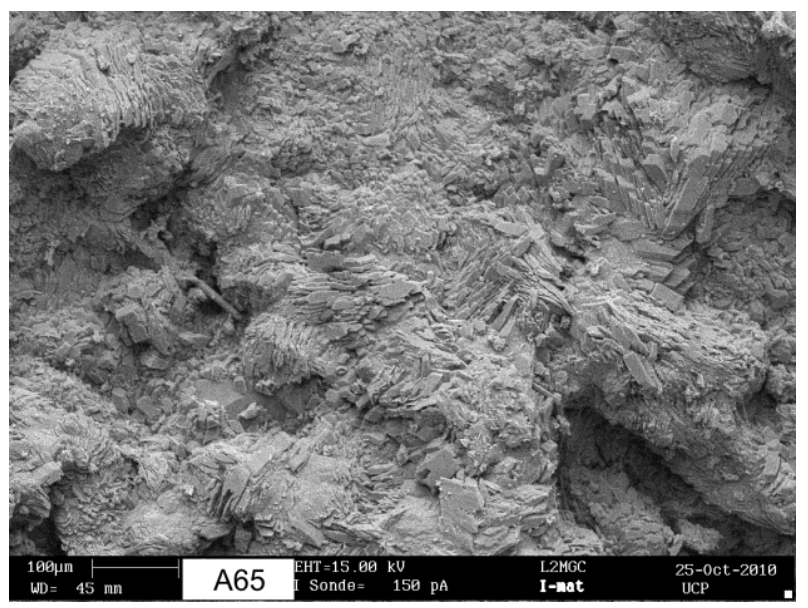

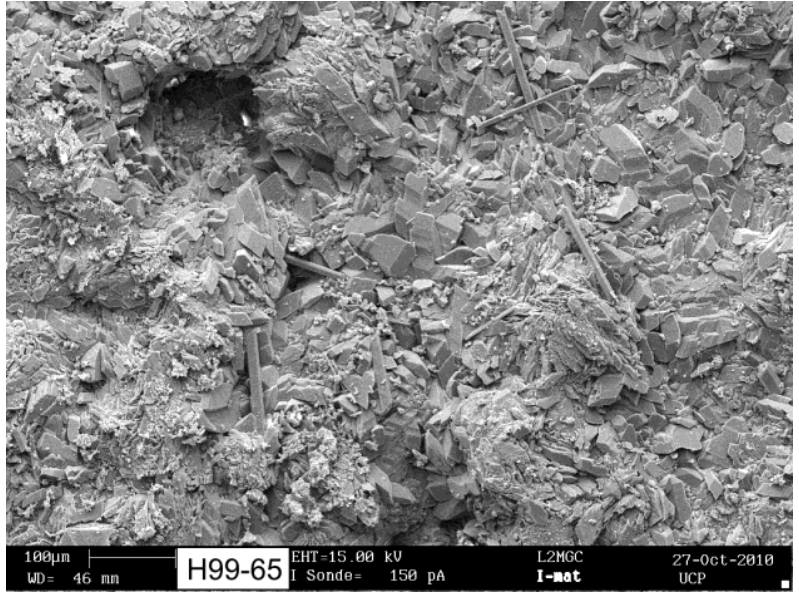

b

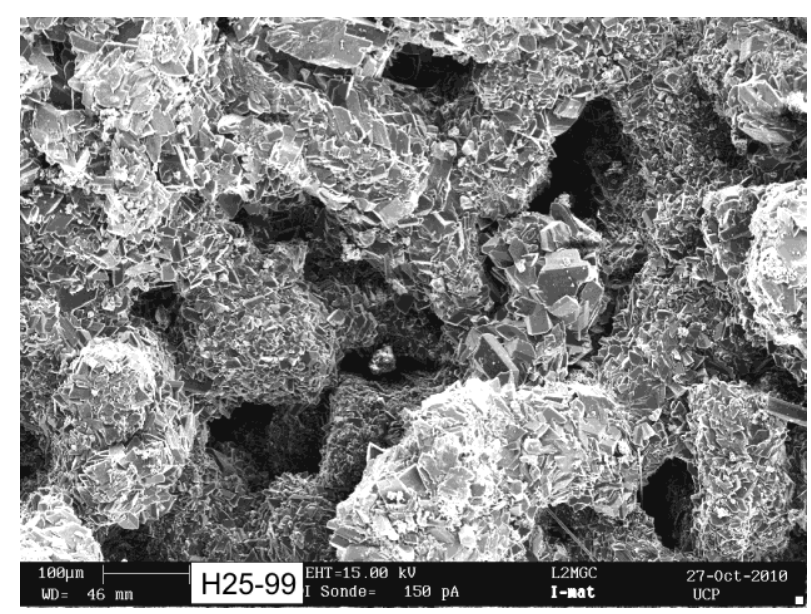

d

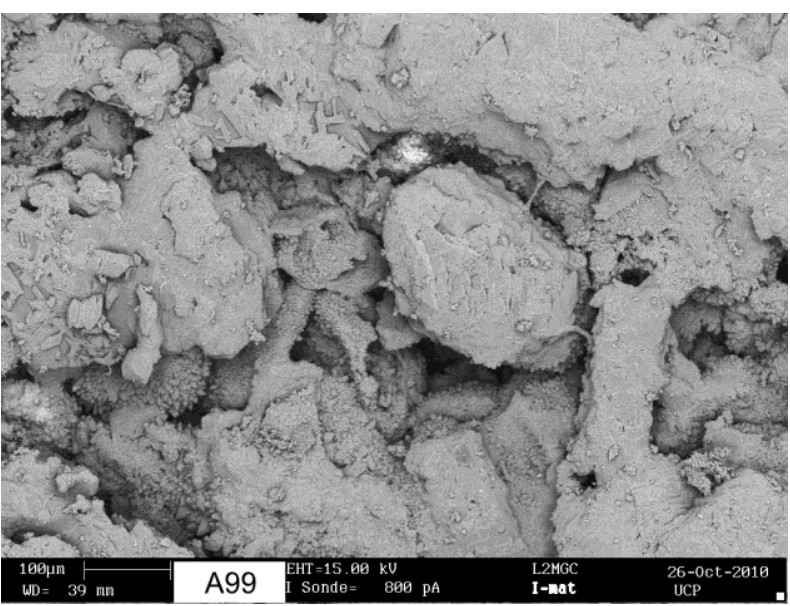

f 


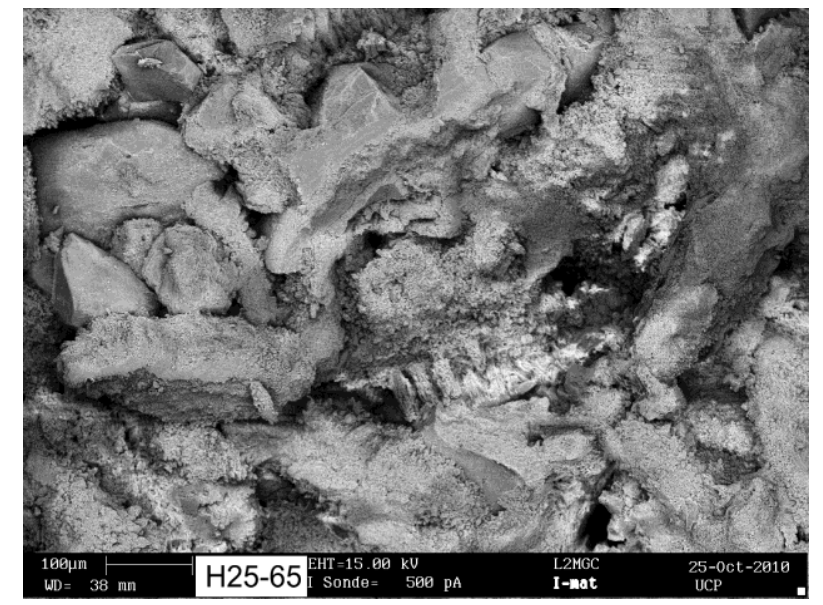

$\mathrm{g}$

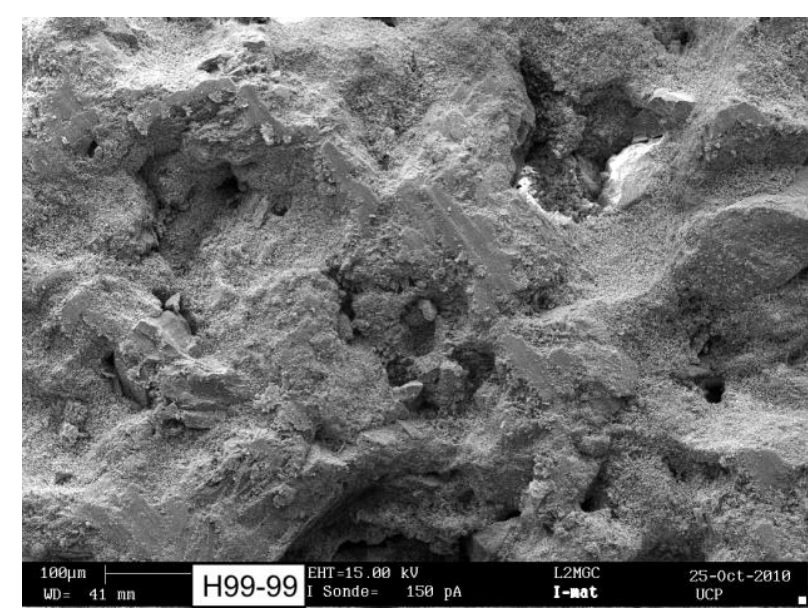

i

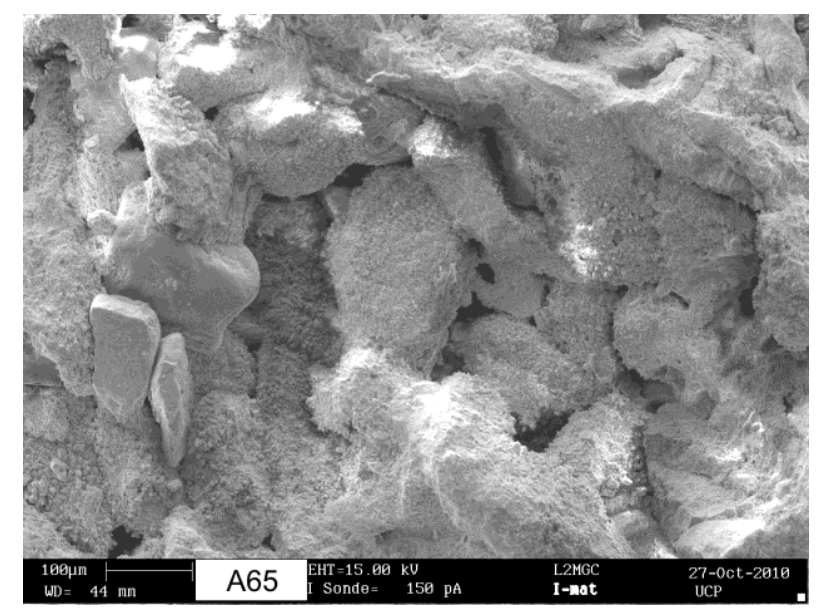

$\mathrm{k}$
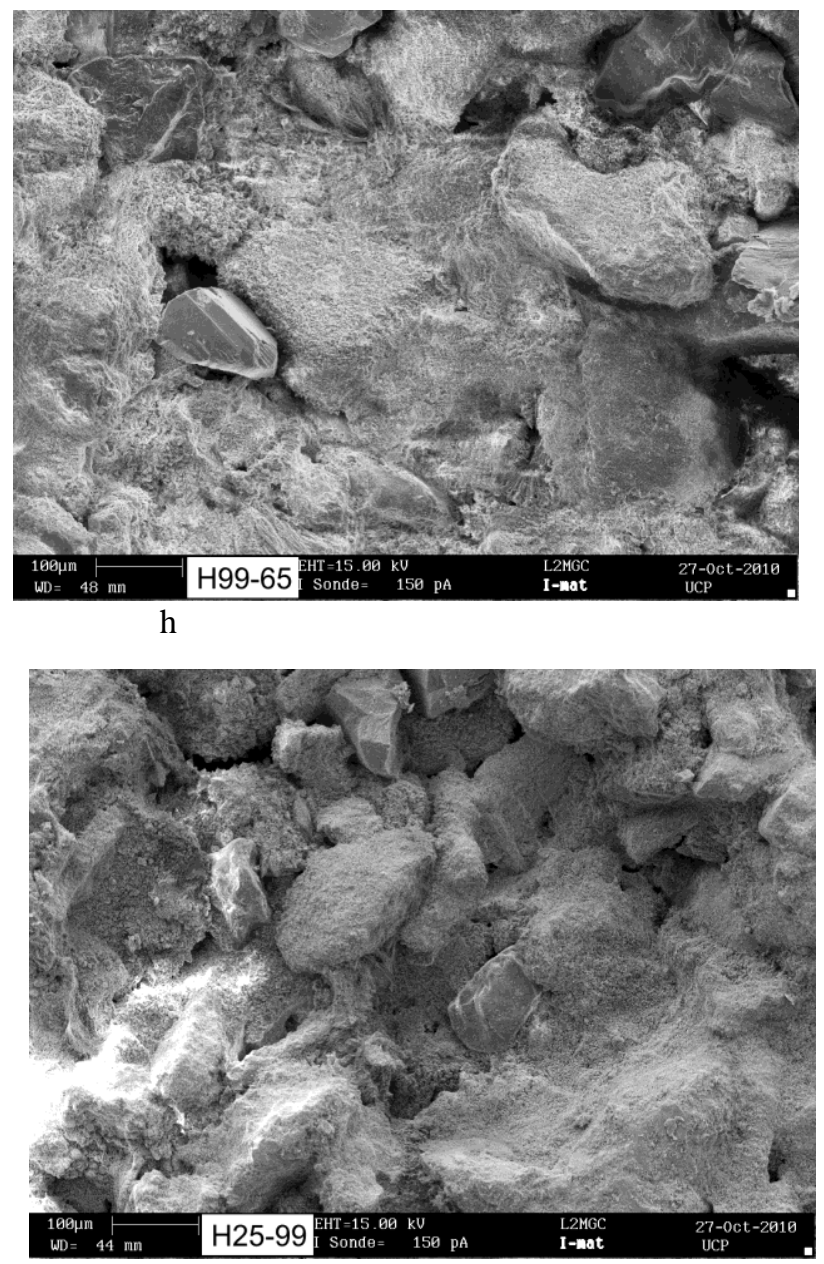

$\mathrm{j}$

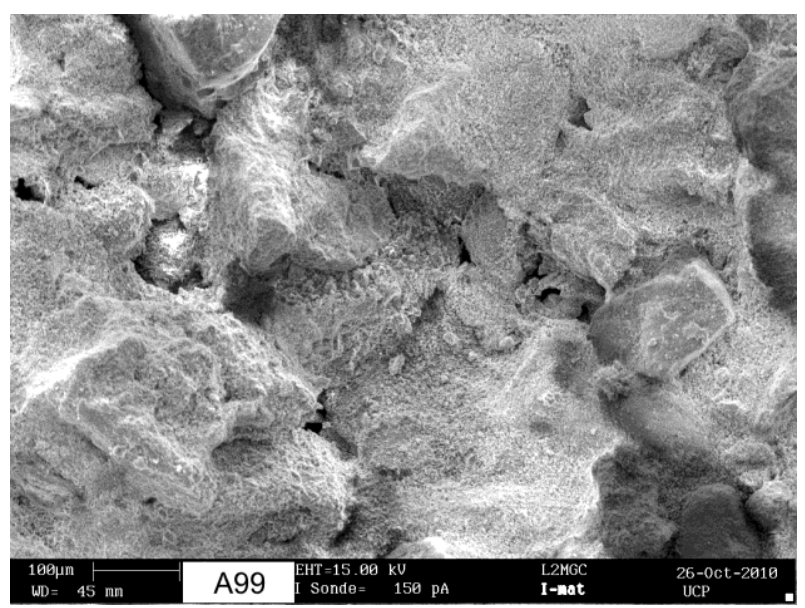

1

Fig 5 a) to f) SEM pictures of the surface of the samples for all the samples. g) to l) pictures of the saw inner surface 

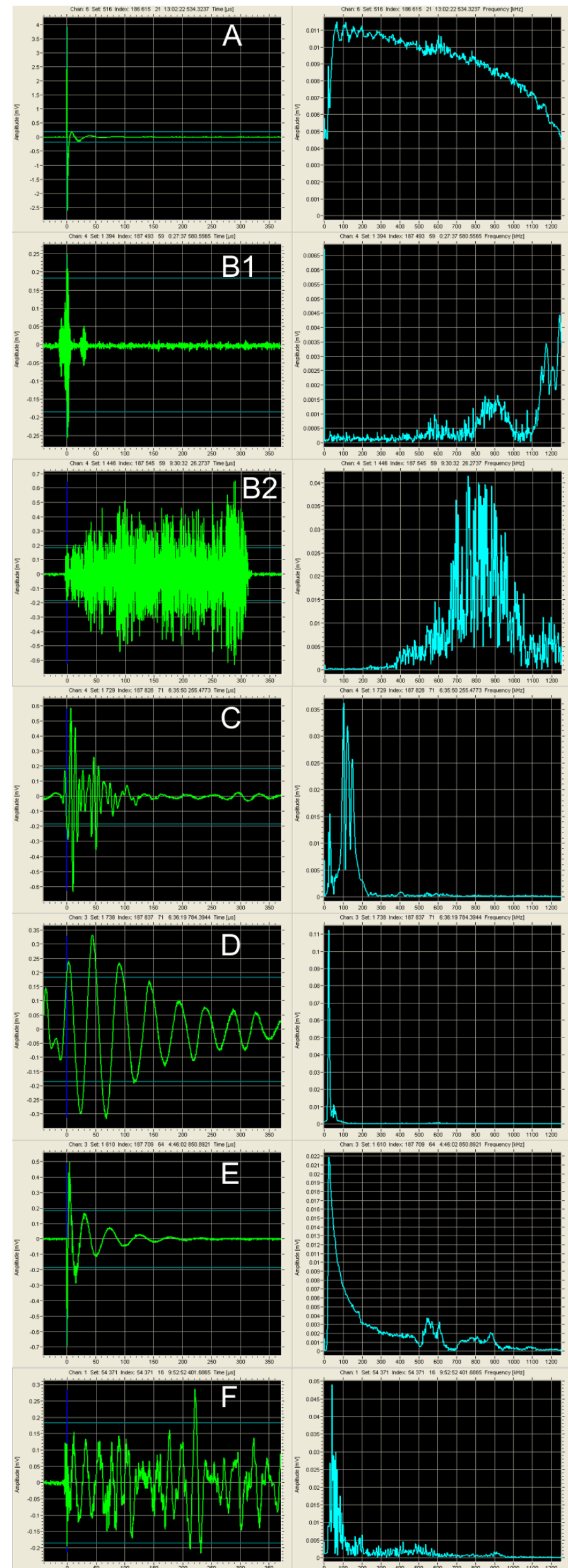

Fig. 6 Different types of signals recorded, from top to bottom. Types A and B correspond to high frequency signals, types $\mathrm{C}, \mathrm{D}$ and $\mathrm{E}$ correspond to low frequency signals. The bottom figure $(\mathrm{F})$ is an example of a signal recorded during the free crystallization tests. 


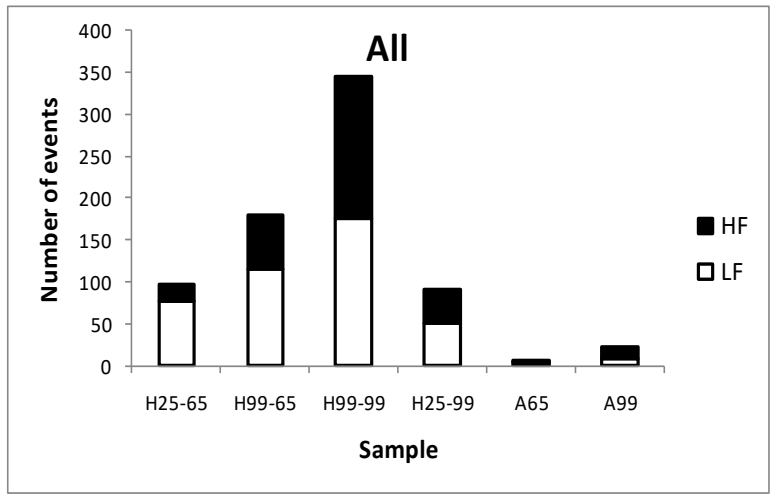

a

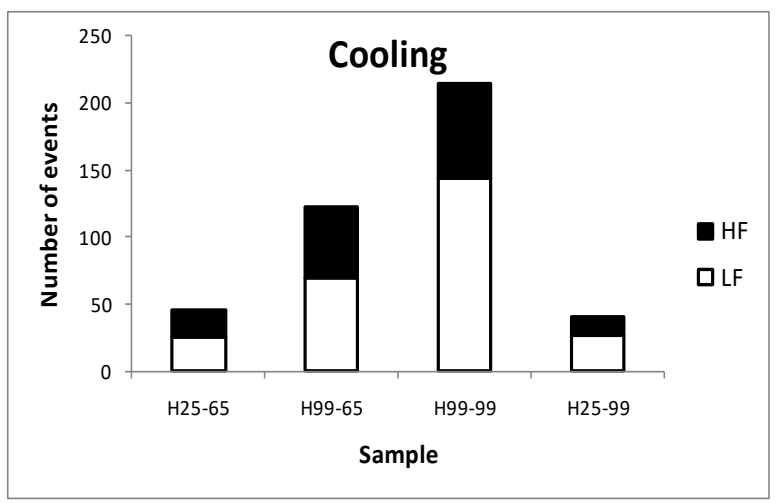

C

Fig. 7 Total number of AE hits generated after 16 cycles for each sample. White bars correspond to the low frequency hits and black bars to the high frequency hits. a) total number of hits, b) hits during drying phase, c) hits during cooling phase and d) during saturation with the salt solution
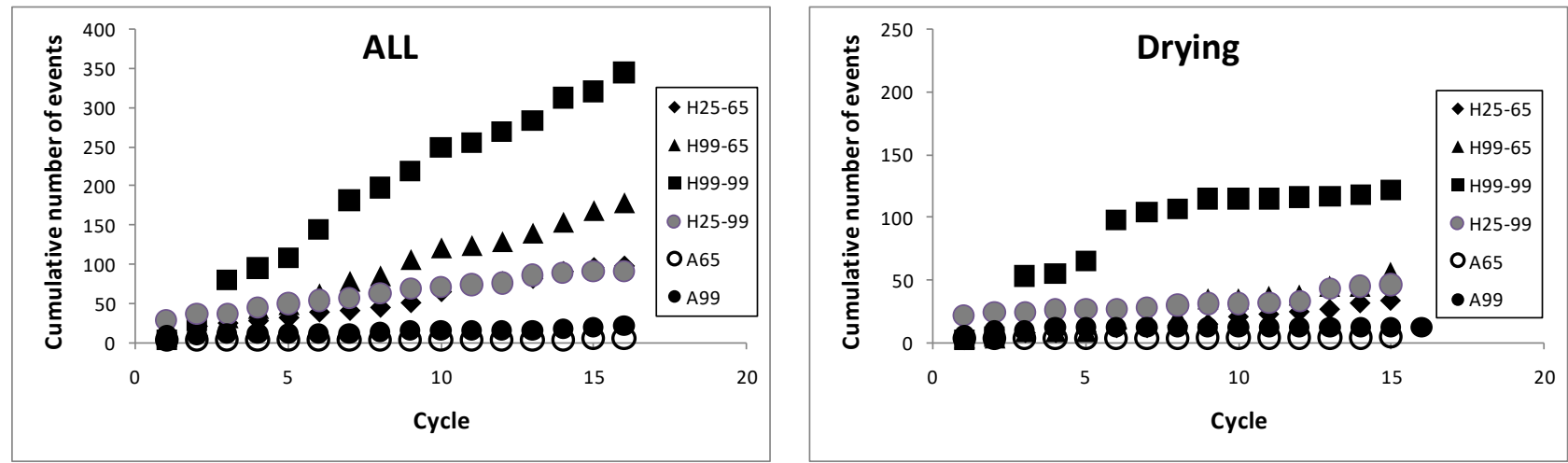

a

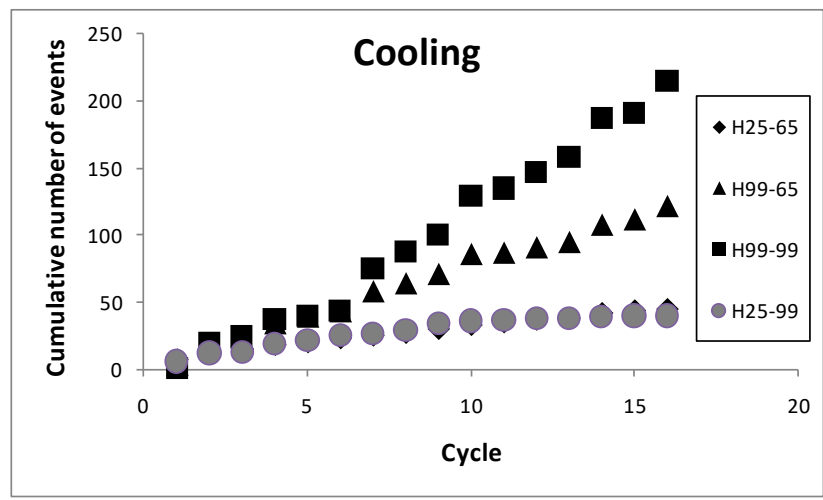

C

Fig. 8 Evolution of the number of AE hits generated as a function of cycle (a) for the total cycle and for the different phases of the cycles : (b) Drying, (c) Cooling and (d) Saturation.

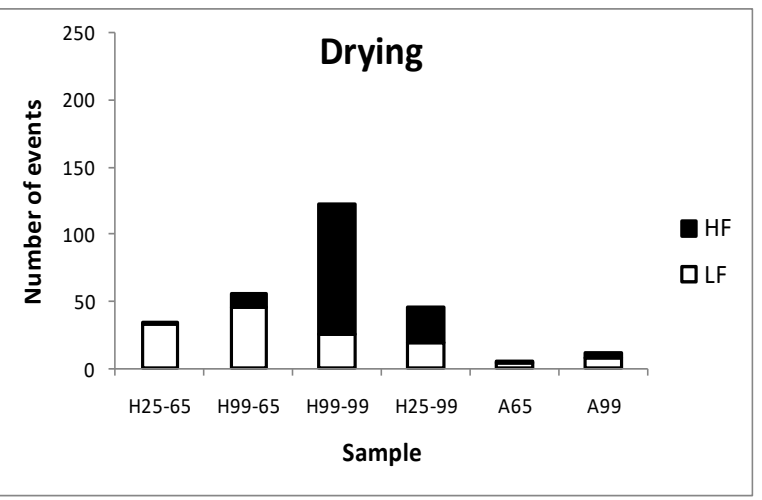

b

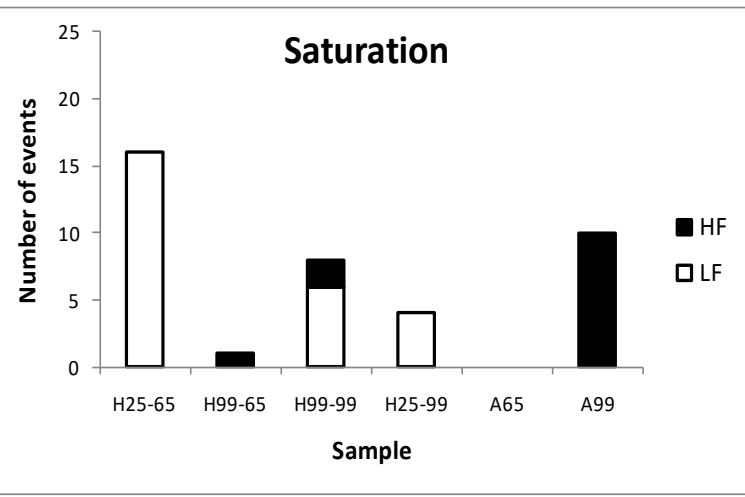

d b

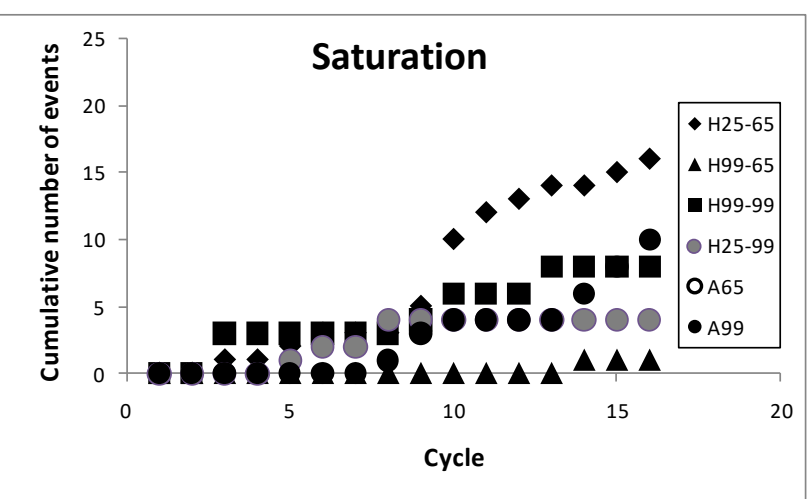

d 


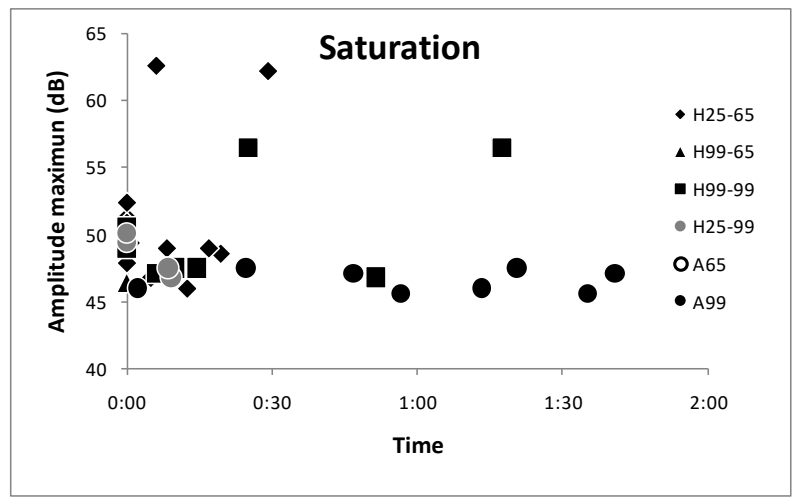

a

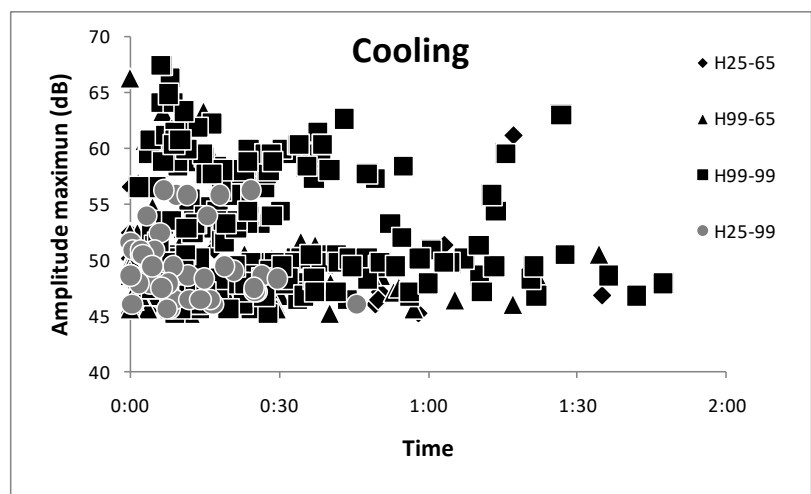

C

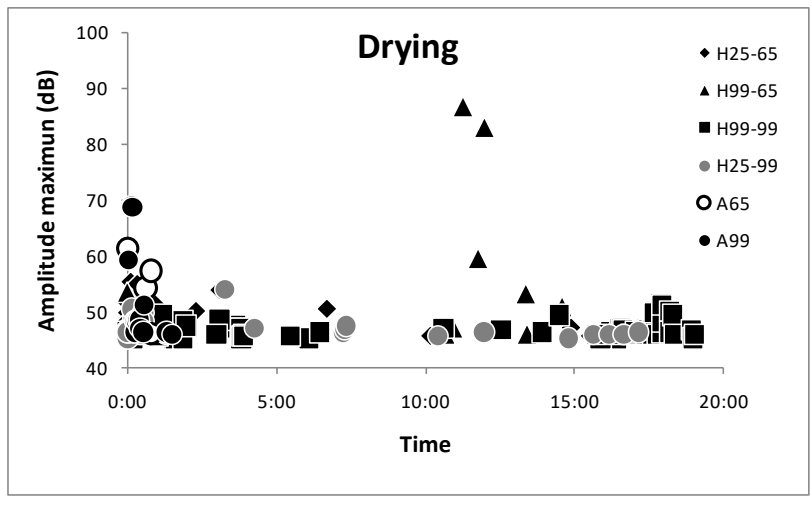

b

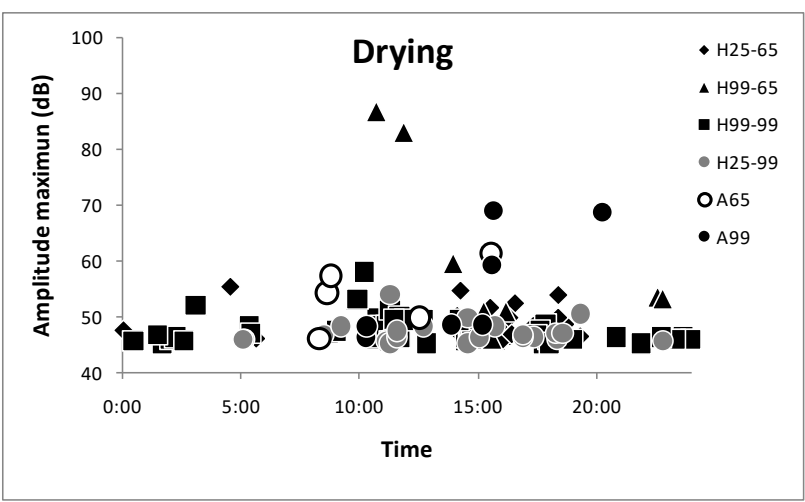

d

Fig. 9 Distribution of the AE generated during each stage for all the cycles. Fig d corresponds to Fig b but with the maximum amplitude plotted vs. clock time and not as a function of time elapsed from the beginning of the drying phase. 


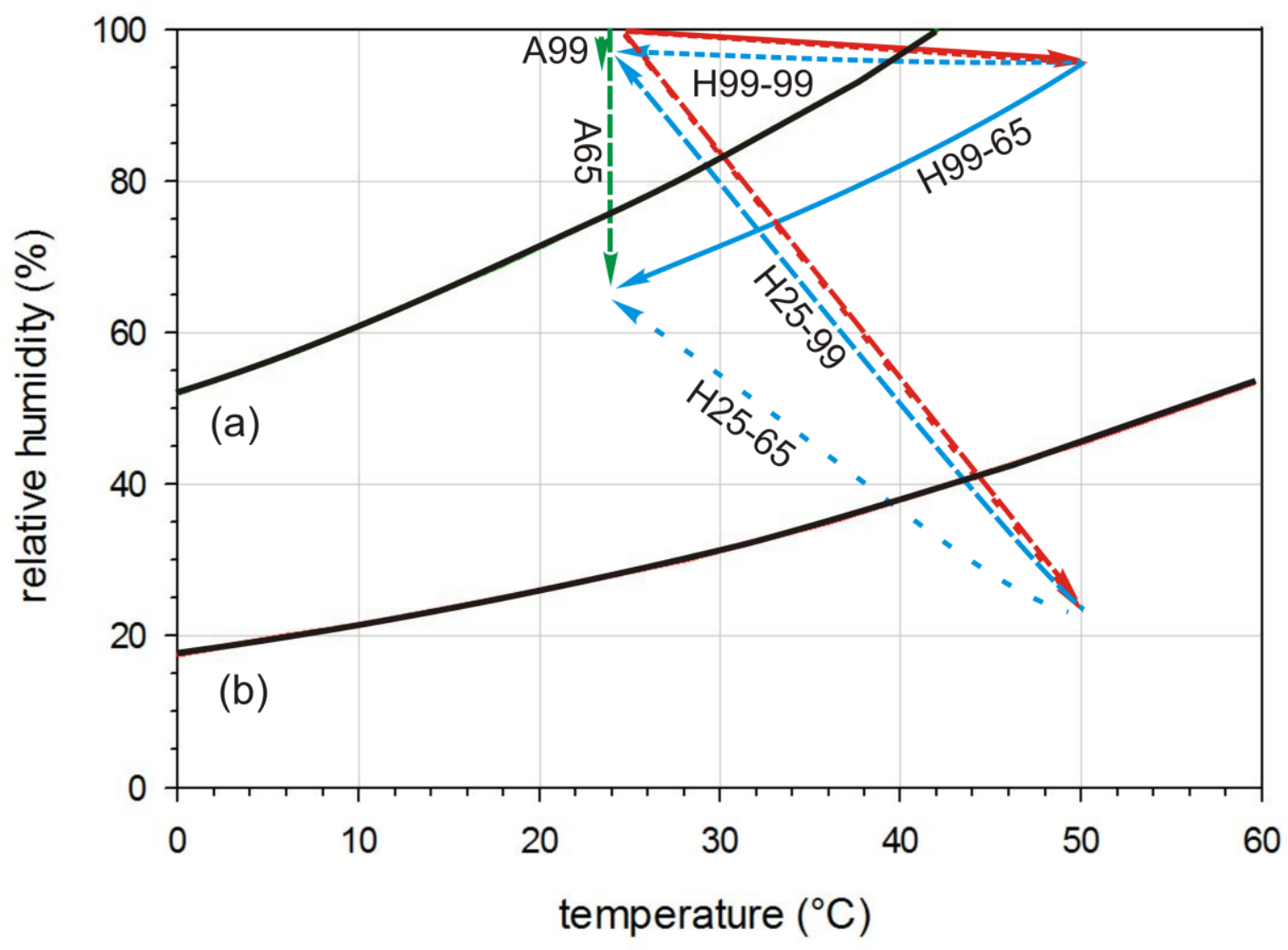

Fig. 10 Drying and cooling path s followed by the different samples. As background the $\mathrm{CaSO}_{4}$ phase diagram proposed by Charola et al. (2007). Curve (a) correspond to gypsum-anhydrite equilibrium and curve (b) to the gypsum-hemihydrated equilibrium. Red lines represent drying paths, and blue lines, cooling paths at $50^{\circ} \mathrm{C}(\mathrm{H}$ samples), and green lines drying paths at $25^{\circ} \mathrm{C}$ (A samples). 


\begin{tabular}{|c|c|c|c|c|c|}
\hline $\begin{array}{c}\text { Sample } \\
\text { name }\end{array}$ & $\begin{array}{c}\text { AE } \\
\text { channel }\end{array}$ & $\begin{array}{c}\text { Drying } \\
\text { temperature }\end{array}$ & $\begin{array}{c}\text { Drying relative } \\
\text { humidity }\end{array}$ & $\begin{array}{c}\text { Cooling relative } \\
\text { humidity }\end{array}$ & $\begin{array}{c}\text { Mass increase } \\
\text { after 12 cycles }\end{array}$ \\
\hline $\mathrm{H} 25-65$ & $\mathrm{CH} 1$ & Heated $-50^{\circ} \mathrm{C}$ & $25 \%$ & $65 \%$ & $<2 \%$ \\
\hline $\mathrm{H} 99-65$ & $\mathrm{CH} 2$ & Heated $-50^{\circ} \mathrm{C}$ & $99 \%$ & $65 \%$ & $<10 \%$ \\
\hline $\mathrm{H} 99-99$ & $\mathrm{CH} 3$ & Heated $-50^{\circ} \mathrm{C}$ & $99 \%$ & $99 \%$ & $<10 \%$ \\
\hline $\mathrm{H} 25-99$ & $\mathrm{CH} 4$ & Heated $-50^{\circ} \mathrm{C}$ & $25 \%$ & $99 \%$ & $<2 \%$ \\
\hline $\mathrm{A} 65$ & CH 5 & Ambient $-25^{\circ} \mathrm{C}$ & \multicolumn{2}{|c|}{$65 \%$} & $<6 \%$ \\
\hline $\mathrm{A} 99$ & $\mathrm{CH} 6$ & Ambient $-25^{\circ} \mathrm{C}$ & \multicolumn{2}{|c|}{$99 \%$} & $<16 \%$ \\
\hline
\end{tabular}

Table 1 Details of the drying and cooling environmental conditions during the weathering tests.

\begin{tabular}{|c|c|c|c|c|c|c|c|c|c|c|c|c|c|c|}
\hline & \multicolumn{12}{|c|}{ CRYSTALLIZATION CYCLES (filtered signal data) } & & \\
\hline & \multicolumn{12}{|c|}{ DRYING } & & \\
\hline & \multicolumn{2}{|c|}{ \# hits } & \multicolumn{2}{|c|}{$\mathrm{A}(\mathrm{dB})$} & \multicolumn{2}{|c|}{$\mathrm{R}(\mu \mathrm{s})$} & \multicolumn{2}{|c|}{$\mathrm{D}(\mu \mathrm{s})$} & \multicolumn{2}{|c|}{ \# Counts } & \multicolumn{2}{|c|}{$\mathrm{E}(\mathrm{eu})$} & \multicolumn{2}{|c|}{ Peak F $(\mathrm{kHz})$} \\
\hline & LF & $\mathrm{HF}$ & LF & $\mathrm{HF}$ & LF & $\mathrm{HF}$ & LF & $\mathrm{HF}$ & LF & $\mathrm{HF}$ & LF & $\mathrm{HF}$ & LF & $\mathrm{HF}$ \\
\hline $\mathrm{H} 25-65$ & 33 & 1 & 48,8 & 47,1 & 2,4 & 0,2 & 25,9 & 0,4 & 1,5 & 1 & 9,6 & 23 & 45,4 & 518 \\
\hline H99-65 & 45 & 11 & 59,3 & 48,8 & 41,6 & 0,5 & 486,6 & 26,5 & 11,7 & 5,2 & 177,5 & 4,8 & 46,7 & 611,6 \\
\hline H99-99 & 25 & 97 & 53,0 & 46,9 & 8,5 & 24,7 & 62,1 & 48,5 & 3,8 & 6,5 & 19,6 & 5,9 & 49,8 & 905,5 \\
\hline H25-99 & 19 & 27 & 47,3 & 46,7 & 0,2 & 2,7 & 0,7 & 21,7 & 1 & 2,6 & 2,7 & 2,4 & 36,7 & 899,7 \\
\hline A65 & 4 & 1 & 55,7 & 46 & 1,6 & 0,2 & 21,4 & 0,2 & 2,8 & 0,2 & 14,2 & 1,7 & 49 & 615 \\
\hline A99 & 8 & 4 & 54,2 & 48,1 & 2,4 & 3 & 37,6 & 17 & 2,1 & 17 & 22,6 & 3,8 & 49 & 781,3 \\
\hline
\end{tabular}

\begin{tabular}{|c|c|c|c|c|c|c|c|c|c|c|c|c|c|c|}
\hline & \multicolumn{14}{|c|}{ COOLING } \\
\hline & \multicolumn{2}{|c|}{ \# hits } & \multicolumn{2}{|c|}{$\mathrm{A}(\mathrm{dB})$} & \multicolumn{2}{|c|}{$\mathrm{R}(\mu \mathrm{s})$} & \multicolumn{2}{|c|}{$\mathrm{D}(\mu \mathrm{s})$} & \multicolumn{2}{|c|}{ \# Counts } & \multicolumn{2}{|c|}{$\mathrm{E}(\mathrm{eu})$} & \multicolumn{2}{|c|}{ Peak F $(\mathrm{kHz})$} \\
\hline & $\overline{L F}$ & $\mathrm{HF}$ & $\mathrm{LF}$ & $\mathrm{HF}$ & $\mathrm{LF}$ & $\mathrm{HF}$ & LF & $\mathrm{HF}$ & $\overline{L F}$ & $\mathrm{HF}$ & $\mathrm{LF}$ & $\mathrm{HF}$ & $\overline{L F}$ & $\mathrm{HF}$ \\
\hline H25-65 & 25 & 20 & 49,0 & 47,5 & 10 & 1,9 & 171,1 & 3,3 & 4,7 & 1,6 & 26,4 & 2,2 & 49 & 551,1 \\
\hline H99-65 & 70 & 52 & 49,8 & 49,8 & 3,3 & 2,5 & 21,7 & 11,4 & 2 & 4,1 & 9,9 & 4,4 & 50,1 & 601,8 \\
\hline H99-99 & 144 & 71 & 54,4 & 50,3 & 2,8 & 5,4 & 28,1 & 13,7 & 1,9 & 2,9 & 11,7 & 3,6 & 49,9 & 620,1 \\
\hline H25-99 & 27 & 13 & 50,0 & 48,8 & 5,7 & 1,6 & 32,5 & 3,5 & 2 & 1,9 & 7,7 & 2,8 & 56,2 & 580,8 \\
\hline
\end{tabular}

Table 2 Acoustic emission parameters of the salt weathering experiments. The selected parameters are number of hits, maximum amplitude (dB), rising time ( $\mu$ s), duration

$(\mu \mathrm{s})$, number of counts per hit, energy $(\mathrm{eu})$, and peak frequency $(\mathrm{kHz})$. 


\begin{tabular}{|c|c|c|c|c|c|c|c|}
\hline & \multicolumn{7}{|c|}{ FREE CRYSTALLIZATION } \\
\cline { 2 - 8 } & \multicolumn{7}{|c|}{ DRYING } \\
\cline { 2 - 8 } & \# hits & A (dB) & R $(\mu \mathrm{s})$ & D $(\mu \mathrm{s})$ & \# Counts & E (eu) & Peak F $(\mathrm{kHz})$ \\
\cline { 2 - 8 } & $\mathrm{LF}$ & $\mathrm{LF}$ & $\mathrm{LF}$ & $\mathrm{LF}$ & $\mathrm{LF}$ & $\mathrm{LF}$ & $\mathrm{LF}$ \\
\hline $50^{\circ} \mathrm{C}-25 \%$ & 9 & 47,8 & 101,5 & 168,4 & 3,7 & 36,2 & 46,8 \\
\hline $50^{\circ} \mathrm{C}-99 \%$ & 591 & 51,2 & 15,1 & 106,4 & 12,8 & 26,3 & 207,3 \\
\hline
\end{tabular}

\begin{tabular}{|c|c|c|c|c|c|c|c|}
\hline & \multicolumn{7}{|c|}{ COOLING } \\
\hline & \# hits & $\mathrm{A}(\mathrm{dB})$ & $\mathrm{R}(\mu \mathrm{s})$ & $\mathrm{D}(\mu \mathrm{s})$ & \# Counts & $\mathrm{E}(\mathrm{eu})$ & Peak F $(\mathrm{kHz})$ \\
\hline & $\mathrm{LF}$ & $\mathrm{LF}$ & $\mathrm{LF}$ & $\mathrm{LF}$ & $\mathrm{LF}$ & LF & LF \\
\hline $65 \%$ & 11 & 48,0 & 20 & 51,7 & 1,3 & 13,8 & 50,5 \\
\hline $99 \%$ & 1 & 47,1 & 15,5 & 42,6 & 1 & 19,2 & 29 \\
\hline
\end{tabular}

Table 3 Same as Table 2 for the free crystallization tests. 